\title{
Determinants of the Implied Shadow Exchange Rates from a Target Zone
}

\author{
Rangvid, Jesper; Sørensen, Carsten
}

Document Version

Final published version

Publication date:

1998

License

CC BY-NC-ND

Citation for published version (APA):

Rangvid, J., \& Sørensen, C. (1998). Determinants of the Implied Shadow Exchange Rates from a Target Zone. Institut for Finansiering, Copenhagen Business School. Working Papers / Department of Finance. Copenhagen Business School No. 1998-15

Link to publication in CBS Research Portal

\footnotetext{
General rights

Copyright and moral rights for the publications made accessible in the public portal are retained by the authors and/or other copyright owners and it is a condition of accessing publications that users recognise and abide by the legal requirements associated with these rights.

Take down policy

If you believe that this document breaches copyright please contact us (research.lib@cbs.dk) providing details, and we will remove access to the work immediately and investigate your claim.
}

Download date: 26. Apr. 2023 
WP 1998-15

Determinants of the implied Shadow Exchange Rates from a Target Zone

af

Jesper Rangvid \& Carsten Sørensen

INSTITUT FOR FINANSIERING, Handelshøjskolen i København

Solbjerg Plads 3, 2000 Frederiksberg C

tlf.: 38153615 fax: 38153600

DEPARTMENT OF FINANCE, Copenhagen Business School

Solbjerg Plads 3, DK - 2000 Frederiksberg C, Denmark

Phone (+45)38153615, Fax (+45)38153600

www.cbs.dk/departments/finance

ISBN 87-90705-14-9

ISSN 0903-0352 


\title{
Determinants of the implied shadow exchange rates from a target zone
}

\author{
Jesper Rangvid and Carsten Sørensen* \\ Department of Finance \\ Copenhagen Business School \\ Rosenørns Allé 31 \\ DK-1970 Frederiksberg \\ Denmark
}

December 1998

${ }^{*}$ We thank Gabriele Becker at BIS and Heino Bohn and Niels Lynggård Hansen at Danmarks Nationalbank for providing us with the data used in the paper. Comments and suggestions from Tom Berglund, Stephen Christophe, Harald Uhlig, two anonymous referees and participants at the EFA meeting in Fontainebleau, the ESEM-EEA meetings in Berlin, and the FMA meeting in Chicago are appreciated. Carsten Sørensen acknowledges financial support from the Danish Natural Science and Social Science Research Councils. 


\begin{abstract}
The paper provides a continuous time model of the dynamic behavior of exchange rates and interest rates when exchange rates are managed within a target zone with the possibility of realignments. In the case of a realignment the exchange rate jumps to a shadow exchange rate. The timing of realignments is modellled by a Cox process with an intensity that depends on the location of the exchange rate in the target zone band as well as the distance to the shadow exchange rate. We set up an approximate maximum likelihood estimation approach and provide parameter estimates for six ERM target zones. Moreover, in the empirical analysis we filter out the shadow exchange rates and investigate which fundamental macroeconomic factors are able to explain the short run and long run behavior of the filtered shadow exchange rates.
\end{abstract}




\section{Introduction}

The paper investigates the behavior of exchange rates and interest rates within a target zone by analyzing empirically the Exchange Rate Mechanism (ERM) within the European Monetary System during the period form March 1979 to June 1997. The target zones within the European Monetary System provide an interesting and unique case for examining issues concerning how monetary policy affects the behavior of exchange rates, interest rates, and other important macroeconomic variables. In particular, the exchange rate regime experienced some stable and unstable periods. Thus, at several occasions there were "speculative attacks" on a number of currencies which eventually lead to the de facto suspension of the target zone regime in August 1993 where the bands were extended to thirty percent for most of the currencies involved.

It remains an open question whether the unstable periods of the ERM within the European Monetary System were caused by macroeconomic variables and exchange rates being fundamentally misaligned or whether the speculative attacks were basically driven by agents suddenly changing beliefs with respect to the sustainability of a given target zone (see e.g. Obstfeld, 1996, and Velasco, 1996).

We use a two step procedure in order to analyze how the behavior of the exchange rates and interest rates within the ERM can be explained by fundamental macroeconomic factors. In the first step, we present and estimate a bilateral continuous time model where the exchange rate jumps to a shadow exchange rate whenever a realignment happens. The shadow exchange rate can be thought of as the natural, or fundamental, level of the exchange rate if there was no target zone regime. An important feature of the modelling is that we can filter out the shadow exchange rate from the continuous time empirical analysis. In the second step, we investigate whether basic macroeconomic variables can explain the short run and long run movements of the filtered shadow exchange rates.

The continuous time target zone model shares some basic ideas with the model in Christensen et al. (1998) in the sense that it allows for realignments described by a Poisson process with a stochastic intensity; a so-called Cox process. Basically, the exchange rate is restricted to move within a band and can only leave the band by a realignment jump. The intensity for a realignment depends on the position of the exchange rate within the band and the distance to the shadow exchange rate. We will assume "uncovered interest rate parity" in order to 
filter out the shadow exchange rate. ${ }^{1,2}$ The target zone model in this paper mainly differs from the model in Christensen et al. (1998) by the functional form of the drift and volatility of the managed exchange rate as well as the realignment intensity.

We set up an estimation approach for the continuous time model and provide parameter estimates for the different European currencies that have been engaged in the ERM since the start in March 1979. The shadow exchange rate is filtered out using the parameter estimates obtained by an approximate maximum likelihood procedure. In the approximate maximum likelihood procedure we substitute the true transition density of the exchange rate, described by a stochastic differential equation, with its discrete time counterpart. Moreover, we assume that the model facilitates a sequential cut, in the sense of Engle et al. (1983), in order to focus on the estimation of the parameters necessary to filter out the shadow exchange rate at the various observation dates.

The empirical target zone analysis in this paper is especially analogue to the empirical analyses in Bekaert \& Gray (1998) and Li (1998). ${ }^{3}$ In particular, Bekaert \& Gray (1998) and $\mathrm{Li}$ (1998) also incorporate stochastic realignment risk but explicitly specify the macroeconomic variables which are assumed to determine the realignment probabilities; moreover, Li (1998) provides a small survey of related literature that she builds on and extends. This differs from the set up in this paper where the implied shadow exchange rate is intended to summarize the relevant information about macroeconomic variables in the formal continuous time target zone model.

After filtering out the shadow exchange rates at the various parameter estimates, we analyze whether macroeconomic variables can explain the observed path of the difference between the shadow exchange rate and the managed exchange rate (the degree of misalignment) during the period surrounding the ERM turbulence in 1992-1993. Conceptually, this investigation is in the spirit of the approach in Svensson (1993) and a number of papers extending on his approach, e.g. Lindberg et al. (1993), Chen \& Giovannini (1994, 1997), and Rose \& Svensson (1994); however, these authors analyze expected realignments whereas we

\footnotetext{
${ }^{1}$ In the appendix, we demonstrate the consistency of "uncovered interest rate parity" with a specific equilibrium pricing structure in the economy and describe briefly how the model is used for pricing exchange rate contingent claims.

${ }^{2}$ The filtering of the shadow exchange rate differs from the simple linear filter in Flood et al. (1991) and Flood \& Rose (1995) especially due to the formal model of a non-credible target zone used in this paper.

${ }^{3}$ Whereas the specific estimation procedure in Bekaert \& Gray (1998) also relies on a maximum likelihood approach, Li (1998) uses a Bayesian approach.
} 
look upon the degree of misalignment. ${ }^{4}$ Using six macroeconomic variables, we run simple regression analyses in order to investigate which variables are able to explain the filtered degrees of misalignment. In line with the results in Campa \& Chang (1998), we find exchange reserves to be an important determinant of the degree of misalignment across the involved ERM exchange rates.

In addition to the regression analysis of the short-run behavior of the degree of misalignment during the 1992-1993 ERM turmoil, we furthermore try to establish some basic results concerning the long-run determinants of the levels of the filtered shadow exchange rates. To this end, we rely on the standard monetary approach to exchange rates. Especially, we investigate whether the shadow exchange rates can on the long run be described by relative (i.e. the home country versus German) money supplies and relative levels of production by means of a cointegration analysis. The use of cointegration analysis is natural in this context as it takes the possibility of non-stationarity in the levels of the series into account. Basically, we find a monetary equation to be valid on the long run for all of the involved shadow exchange rates except the French franc versus German mark.

The paper is organized as follows. In Section 2 we describe the continuous time target zone model. We set up an approximate maximum likelihood estimation approach in Section 3. In Section 4 we report the parameter estimates of the target zone model and investigate the macroeconomic determinants of the filtered shadow exchange rates. Section 5 concludes. The appendix describes the relevant pricing kernel in the economy and how to price exchange rate contingent claims.

\section{The continuous time target zone model}

The dynamics are in the following continuous time model described by a two-dimensional wiener process $\left(W_{1 t}, W_{2 t}\right)$, with a correlation coefficient $\rho$, and a jump process $N_{t}$ which can be thought of as a Poisson process where the intensity is described by a stochastic process $\lambda_{t}$; formally $N_{t}$ is a so-called Cox process. The basic idea in the target zone modelling is to restrict the exchange rate to move within a band unless a realignment occurs. Within the band, the exchange rate is described by a standard stochastic differential equation. Furthermore, realignments occur just as jumps in a Cox process. The intensity for jumps, in particular,

\footnotetext{
${ }^{4}$ The model allows us to filter out the probabilities of devaluations as well, though, we focus here on the series for the shadow exchange rates.
} 
depends on the position of the exchange rate within the band as well as how misaligned the exchange rate is relatively to some "fundamental" which we will refer to as the shadow exchange rate. The shadow exchange rate can be interpreted as the natural level for the exchange rate if the target zone regime is suspended.

\subsection{The exchange rate dynamics}

As described above, the exchange rate is restricted to move within a band in time periods without realignments. Whenever a realignment happens, the exchange rate jumps to a shadow exchange rate. The dynamics of the (log-) shadow exchange rate, $f_{t}$, are described by a stochastic differential equation on the form,

$$
d f_{t}=\mu d t+\sigma d W_{1 t}
$$

where $\mu$ and $\sigma$ are constant parameters. The parameter $\mu$ describes the expected change in the shadow exchange rate whereas $\sigma$ is the volatility of the shadow exchange rate.

We will use the convention that the exchange rate is the price of the foreign currency in units of the domestic currency. Moreover, for all specific exchange rates in the paper, we use the convention that the German mark is the foreign currency so that the exchange rate always refers to the price of the German mark in different local currencies.

The dynamics of the logarithm to the exchange rate, $x_{t}$, are described by,

$$
d x_{t}=\left[a\left(\theta_{t}-x_{t}\right)+b_{t}\left(f_{t}-x_{t}\right)\right] d t+\delta \sqrt{\frac{4\left(u_{t}-x_{t}\right)\left(x_{t}-l_{t}\right)}{\left(u_{t}-l_{t}\right)^{2}}} d W_{2 t}+\epsilon_{t} d N_{t}
$$

where

$$
b_{t} \equiv b\left(x_{t}, \theta_{t}, l_{t}, u_{t}\right)= \begin{cases}\kappa\left(\frac{u_{t}-x_{t}}{u_{t}-\theta_{t}}\right) & \text { if } \theta_{t}<x_{t}<f_{t} \\ \kappa\left(\frac{x_{t}-l_{t}}{\theta_{t}-l_{t}}\right) & \text { if } f_{t}<x_{t}<\theta_{t} \\ \kappa & \text { otherwise }\end{cases}
$$

and $a, \kappa$, and $\delta$ are constant parameters. The processes $\theta_{t}, l_{t}$, and $u_{t}$ are the (log-) central parity, the (log-) lower bound of the band, and the (log-) upper bound of the band and, in general, $\theta_{t}=\frac{1}{2} l_{t}+\frac{1}{2} u_{t}$. The jump component in (2) incorporates the possibility of realignments into the model. In particular, $\epsilon_{t}$ describes the jump size of the exchange rate in case of a realignment. We will describe the precise modelling of realignments in the next section. In this section, we will focus on the basic ideas behind the modelling of exchange rate movements and the interpretation and significance of the parameters $a, \kappa$, and $\delta$ when the exchange rate moves within the target zone. 
The parameter $a$ describes the degree of tendency towards the central parity rate. Likewise, the parameter $\kappa$ describes the degree of tendency towards the shadow exchange rate through the function $b\left(x_{t}, \theta_{t}, l_{t}, u_{t}\right)$; this happens in such a way that the tendency evaporates at the boundaries whenever the tendency towards the shadow exchange rate would otherwise pull it outside the exchange rate band. Our specification of the drift rate for the exchange rate differs from the specification in Christensen et al. (1998) where there is no tendency towards the shadow exchange rate whenever the exchange rate is close to the boundaries. In our model, the tendency towards the shadow exchange rate is not zero if, say, the exchange rate is close to the lower boundary and the shadow exchange rate is above the current exchange rate. This seems a more appealing characteristic since, in this case, the tendency towards a shadow exchange rate should tend to pull the exchange rate away from the lower boundary.

The model is formulated in such a way that the volatility of the exchange rate evaporates at the boundaries. The tendency towards the central parity will thus always pull the exchange rate into the band whenever it is close to a boundary - and sometimes helped by the tendency towards the shadow exchange rate, as discussed above. The only way the exchange rate can leave the band is by a jump. The parameter $\delta$ is a volatility parameter for the exchange rate within the band and the model is specified such that $\delta$ can be interpreted as the volatility of the exchange rate when located in the center of the target zone.

\section{[ INSERT FIGURE 1 AND FIGURE 2 ABOUT HERE ]}

The drift and volatility of the managed exchange rate as a function of the exchange rate within a specific target zone band is illustrated in Figure 1 and Figure 2, respectively. The drift rate is a stochastic process, since it is a function of the shadow exchange rate $f_{t}$, and Figure 1 thus only illustrates the form of the drift rate for five different values of the shadow exchange rate. As illustrated by Figure 2, the volatility of the managed exchange rate is highest in the center of the target zone but evaporates rapidly close to the boundaries. On the other hand, the drift rate of the managed exchange rate is always negative (positive) at the upper (lower) boundary so that the managed exchange rate is pulled towards the center of the target zone when located at the boundaries; for a given level of the shadow exchange rate $f_{t}$ the drift rate is linear for some segments but non-linear for other segments in order to obtain this feature at the boundaries. Basically, when the exchange rate is not under pressure the drift is linear. This is e.g. the case if the shadow exchange rate is at the center of the target zone as in the case $f_{t}=0$ in Figure 1 . 


\subsection{Realignments}

The shadow exchange rate $f_{t}$ is defined as the natural level of the exchange rate if a realignment of the band should occur. Realignments usually occur whenever at least one of the currencies in the ERM is under pressure. The involved currencies will usually not be under pressure versus German mark, if the exchange rate is close to the lower boundary of the band. Below, we will start out by describing the timing of realignments and then the model for what happens at a realignment date.

The arrival of realignments is modelled as jumps in a Cox process. This generalizes the jump feature of the target zone modelling by Ball \& Roma (1993) and Dumas et al. (1995) where the realignment intensity is assumed constant. We will assume that the jump intensity for a realignment in any specific currency against the German mark depends on the distance to the central parity of the target zone as well as the distance to the shadow exchange rate. Formally, the jump intensity for a realignment is,

$$
\lambda_{t} \equiv \lambda\left(x_{t}, \theta_{t}, l_{t}, u_{t}, f_{t}\right)=\lambda_{0}+\lambda_{1} \max \left[0,\left(f_{t}-x_{t}\right)\left(\frac{x_{t}-\theta_{t}}{u_{t}-l_{t}}\right)\right]
$$

where $\lambda_{0}$ and $\lambda_{1}$ are constant non-negative parameters. This specification captures the basic characteristics of the probability of a realignment as described above and has some other desirable implications as we will discuss briefly in the following.

If the exchange rate is located above (below) both the central parity and the shadow exchange rate, the specific exchange rate will not be under pressure. In this case, the tendency towards the shadow exchange rate will also adjust the exchange rate towards the central parity and, hence, the divergence from the shadow exchange rate is not a threat to the maintenance of the target zone. The intensity is, in this case, a non-negative constant, $\lambda_{0}$, and potential realignments will occur as occasional general adjustments of the central parities within the ERM or as a consequence of another currency being misaligned under the present parities.

However, if the exchange rate is located in between the central parity and the shadow exchange rate the specific currency might be under pressure since the tendency towards the shadow exchange rate will pull the exchange rate further away from the central parity. In this case, the intensity describing the probability of a realignment is more significant and given by $\lambda_{0}+\lambda_{1}\left(f_{t}-x_{t}\right)\left(x_{t}-\theta_{t}\right)\left(u_{t}-l_{t}\right)^{-1}$. The realignment intensity depends on the current distance to the central parity and the distance to the shadow exchange rate. The distance to the shadow exchange rate, in particular, reflects how far the current exchange rate is from the natural level of the exchange rate if the target zone was suspended and thus describes 
how misaligned the current exchange rate is.

If a realignment occurs, there will be a discrete change in the lower and upper boundary for the exchange rate band and usually a discrete change in the central parity as well. ${ }^{5}$ Moreover, there will be no actions taken by central banks to prevent the exchange rate from jumping to its natural level as reflected by the shadow exchange rate and, hence, there will usually also be a discrete jump in the exchange rate at a realignment date.

The lower and upper boundary of the band are stochastic processes that can be modelled as Cox processes with stochastic intensities and stochastic jump sizes. Likewise, the central parity will be a process of this type. For all the processes, the arrival of jumps is described by $N_{t}$. However, we will not make any specific assumptions on the jump sizes for the processes as this is not crucial for the estimation approach and the filtering of the shadow exchange rates as described in Section $3{ }^{6}$

Finally, we will assume that whenever a realignment occurs, the exchange rate will not necessarily jump exactly to the shadow exchange rate. Rather, the (log- ) exchange rate will jump to the (log-) shadow exchange rate plus some noise described by serially independent and normally distributed stochastic variables with mean zero and standard deviation $\omega$. The jump sizes in equation (2) thus have the form: $\epsilon_{t}=\left(f_{t}-x_{t}\right)+\eta_{t}$ where $\eta_{t} \sim \operatorname{NID}\left(0, \omega^{2}\right)$.

\subsection{The interest rate spread}

We will follow a standard approach in the economic literature and assume "uncovered interest rate parity" in the sense that the short interest rate spread is equal to the expected change in the log-exchange rate. "Uncovered interest rate parity" is often rejected in empirical tests based on floating exchange rates. However, Svensson (1992) argues that the assumption of "uncovered interest rate parity" is more appropriate for managed exchange rates in a target zone, and this is to some extent supported by empirical results in e.g. Bossaerts \& Hillion (1991) and Rose \& Svensson (1995). In addition, imposing "uncovered interest rate parity" places some restrictions on the pricing kernel (for example marginal utilities of a representative agent) in the economy that is relevant for general asset pricing and pricing of exchange rate contingent claims. In the appendix we demonstrate the existence of a

\footnotetext{
${ }^{5}$ We consider all changes in either $\theta_{t}, l_{t}$, or $u_{t}$ as indicators of a realignment. Thus, we consider a change in the width of the band as a realignment even when the central parity is kept constant.

${ }^{6}$ We will assume that the model facilitates a sequential cut in the sense of Engle et al. (1983); the details are given in Section 3 .
} 
pricing kernel process which is consistent with "uncovered interest rate parity" in the sense that the short interest rate spread is equal to the expected change in the log-exchange rate; moreover, the appendix describes how exchange rate contingent claims can be priced within the continuous time target zone model.

By the "uncovered interest rate parity", the interest rate spread in the economy must equal the drift rate in the (log-) exchange rate plus a component representing the expected (log-) exchange rate movement due to a realignment; see equation (2). Let $r_{t}^{D}$ denote the domestic interest rate and let $r_{t}^{F}$ denote the foreign interest rate. From (2), we then have:

$$
r_{t} \equiv r_{t}^{D}-r_{t}^{F}=a\left(\theta_{t}-x_{t}\right)+b_{t}\left(f_{t}-x_{t}\right)+\lambda_{t}\left(f_{t}-x_{t}\right)
$$

The first two terms in the description of the interest rate spread, $r_{t}$, are related to the drift in the exchange rate if the possibility of a realignment is ignored. The third term is related to the expected change in the exchange rate due the possibility of a realignment; the term can be interpreted as a rate of probability for a realignment, $\lambda_{t}$, times the expected jump size, $f_{t}-x_{t}$.

The interest rate spread is an increasing function of the shadow exchange rate. The basic intuition is that the domestic currency will depreciate for high levels of the shadow exchange rate and, in equilibrium, rational investors must be compensated by a relatively high domestic interest rate. Obviously, it is a key feature of the modelling that the depreciation of the domestic currency, for relatively high levels of the shadow exchange rate, may happen either continuously or by a realignment jump.

Likewise, whenever the exchange rate is below (above) the central parity, the tendency towards the central parity will tend to depreciate (appreciate) the domestic currency, and thus induce a high (low) interest rate spread.

Note that, if there was no tendency towards a shadow exchange rate (and, hence, the second term and third term on the right hand side of equation (4) were absent), the exchange rate and the interest rate spread would in fact be perfectly negatively correlated. The negative correlation is entirely due to the tendency away from the boundaries and towards the central parity; this is similar to the implications of the Krugman (1991) model but is not in line with the results from empirical tests as noted in e.g. Bertola \& Caballero (1992). In this perspective, the tendency towards the shadow exchange rate in our model allows for a positive correlation between the exchange rate and the interest rate during periods with pressure on the exchange rate. 


\subsection{Filtration of the shadow exchange rate}

An important feature of the model is that there is an invertible relationship between the interest rate spread and the shadow exchange rate given knowledge of all the other statevariables in the economy (i.e. $x_{t}, l_{t}, u_{t}, \theta_{t}$ ).

We will use this observation to filter out the shadow exchange rate at different time points and in the estimation approach in the following section as well. The relationship between the shadow exchange rate and the interest rate spread in the economy is given by (4). As discussed above, the interest rate spread is monotonically increasing as a function of the shadow exchange rate and, hence, we can invert the relationship and write the shadow exchange rate as a function of the interest rate spread. The interest rate spread is in fact a linear function of the shadow exchange rate for some values of the state-variables and a second order polynomial for other values; this can be seen by inserting the definitions of $b_{t}$ and $\lambda_{t}$ in equation (4). By inverting the relationship, the solution for the shadow exchange rate has the following form:

$$
f_{t}= \begin{cases}x_{t}+\frac{r_{t}+C_{t}}{\kappa+\lambda_{0}} & \text { if }\left(r_{t}+C_{t}\right)\left(x_{t}-\theta_{t}\right) \leq 0 \\ x_{t}+\frac{-B_{t}+\sqrt{B_{t}^{2}+4 A_{t}\left(r_{t}+C_{t}\right)}}{2 A_{t}} & \text { otherwise }\end{cases}
$$

where

$$
\begin{aligned}
A_{t} & =\lambda_{1}\left(\frac{x_{t}-\theta_{t}}{u_{t}-l_{t}}\right) \\
B_{t} & =\left\{\begin{array}{cl}
\kappa\left(\frac{u_{t}-x_{t}}{u_{t}-\theta_{t}}\right)+\lambda_{0} & \text { if } r_{t}+C_{t}>0, x_{t}>\theta_{t} \\
\kappa\left(\frac{x_{t}-l_{t}}{\theta_{t}-l_{t}}\right)+\lambda_{0} & \text { otherwise }
\end{array}\right. \\
C_{t} & =a\left(x_{t}-\theta_{t}\right) .
\end{aligned}
$$

In the estimation approach below, we will think of and refer to $f_{t}$ as an observable variable, similar to the other state-variables involved, though the observability is always understood to be transmitted through (5). Likewise, equation (5) describes how the shadow exchange rate for the subsequent macroeconomic analysis is filtered out.

\section{Target zone model estimation approach}

In this section we describe an approximative maximum likelihood estimation method for the continuous time target zone model in section 2 .

The data are observed at discrete equidistant time points, $t_{i}, i=0, \ldots, I$ and $\Delta=t_{i}-t_{i-1}$.

Whenever convenient, we use the simplifying notation: $x_{i} \equiv x_{t_{i}}, \theta_{i} \equiv \theta_{t_{i}}$ and so on. At 
the $i$ 'th observation date, we observe the exchange rate, the interest rate spread, and the lower and upper boundary of the exchange rate band as well as the central parity. Given a set of parameters, there is an invertible relationship between the interest rate spread and the shadow exchange rate, as solved for in (5). We will therefore occasionally refer to the observed shadow exchange rate rather than the observed interest rate spread, though it is implicitly understood that this observability is transmitted through equation (5). The statevector $S_{i}=\left(x_{i}, f_{i}, \theta_{i}, l_{i}, u_{i}\right)$ thus describes the observed state of the economy at the $i$ 'th time point.

The target zone model in Section 2 is Markovian. Hence, if the conditional densities for the state-vector are analytically known, the log-likelihood function can be formulated and used as a basis for finding maximum likelihood parameter estimates. The conditional densities implied by the continuous time target zone model are, however, not known and maximum likelihood estimation is therefore not directly accessible. The approach taken below is based on approximative maximum likelihood estimation in the sense that the conditional densities are proxied by their counterparts from a discretized version of the stochastic differential system in (1) and (2). The discretized version is based on Euler discretization schemes and has the form,

$$
\begin{aligned}
& f_{i+1}=f_{i}+\mu \Delta+\sigma \tilde{z}_{1, i} \\
& x_{i+1}= \begin{cases}x_{i}+\left[a\left(\theta_{i}-x_{i}\right)+b_{i}\left(f_{i}-x_{i}\right)\right] \Delta+\delta \sqrt{\frac{4\left(u_{i}-x_{i}\right)\left(x_{i}-l_{i}\right)}{\left(u_{i}-l_{i}\right)^{2}}} \tilde{z}_{2, i} & \text { if } J_{i+1}=0 \\
f_{i+1}+\eta_{i+1} & \text { if } J_{i+1}=1\end{cases}
\end{aligned}
$$

where $\left(\tilde{z}_{1, i}, \tilde{z}_{2, i}\right)$ are serially uncorrelated and bivariate normally distributed variables,

$$
\left(\tilde{z}_{1, i}, \tilde{z}_{2, i}\right) \sim \operatorname{NID}(\underline{0}, \Sigma \Delta), \Sigma=\left(\begin{array}{cc}
1 & \rho \\
\rho & 1
\end{array}\right)
$$

and $J_{i+1}$ is an indicator function for a realignment; $J_{i+1} \equiv 1_{\left\{l_{i+1} \neq l_{i}\right\} \cup\left\{u_{i+1} \neq u_{i}\right\}}$. Hence, $J_{i+1}$ takes on the value one if there is a realignment and zero otherwise. If there is a realignment, the exchange rate jumps to the shadow exchange rate plus some noise and this happens in the end of the period; $J_{i+1}=1$ thus indicates a realignment immediately before time $t_{i+1}$.

We will use the following approximation of the probability of no realignment occurring in the interval from $t_{i}$ to $t_{i+1}$ :

$$
\mathrm{E}_{t}\left[e^{-\int_{t_{i}}^{t_{i+1}} \lambda_{u} d u}\right] \approx e^{-\lambda_{i} \Delta}
$$

The left hand side of (8) is an exact characterization of the probability of no realignment; see for example Lando (1994). An analytical solution to the expectations is not known. The 
suggested approximation is obtained by replacing the integral involved on the left hand side of (8) with its left point approximation.

We can solve analytically for the conditional densities implied by the discretized system described by (6), (7), and (8) and this will be used in the final formulation of the log-likelihood problem below.

Similar to the continuous time model, the discretized version is Markovian. The likelihood function is a function of the model parameters (as well as the empirical observations) and is described by the joint density of the observations. The parameters of the model can be summarized as $\Phi=\Phi_{1} \cup \Phi_{2}$ where, in particular, $\Phi_{1}$ is the set of parameters involved in the formal modelling of the exchange rate dynamics in (1), (2), and (3) while $\Phi_{2}$ are parameters describing jump sizes of $\theta_{t}, l_{t}$, and $u_{t}$. The joint density function for the state-variables conditional on the initial state $S_{0}$ can be written on the following form,

$$
\begin{aligned}
p\left(S_{1}, \ldots, S_{I} \mid S_{0} ; \Phi\right) & =\prod_{i=1}^{I} p\left(S_{i} \mid S_{i-1} ; \Phi\right) \\
& =\prod_{i=1}^{I} p\left(x_{i}, f_{i}, J_{i} \mid S_{i-1} ; \Phi\right) p\left(\theta_{i}, l_{i}, u_{i} \mid x_{i}, f_{i}, J_{i}, S_{i-1} ; \Phi\right) \\
& =\prod_{i=1}^{I} p\left(x_{i}, f_{i}, J_{i} \mid S_{i-1} ; \Phi_{1}\right) p\left(\theta_{i}, l_{i}, u_{i} \mid x_{i}, f_{i}, J_{i}, S_{i-1} ; \Phi\right)
\end{aligned}
$$

where $p(\cdot \mid \cdot ; \cdot)$ is used as notation for the conditional densities of the discretized model. In the first equality in (9), we have used the Markovian properties of the model while the second equality is based on an application of Bayes Rule. The last equality follows from the observation that $p\left(x_{i}, f_{i}, J_{i} \mid S_{i-1} ; \Phi\right)=p\left(x_{i}, f_{i}, J_{i} \mid S_{i-1} ; \Phi_{1}\right)$; which essentially just states the fact that the conditional densities for the exchange rate, the shadow exchange rate, and whether a jump occurs or not are functions of the parameters in (6) and (7) as well as the jump probabilities in (3) and (8) only.

We will assume that the density function facilitates a sequential cut; see Engle et al. (1983). Stated formally, we assume that $p\left(\theta_{i}, l_{i}, u_{i} \mid x_{i}, f_{i}, J_{i}, S_{i-1} ; \Phi\right)=p\left(\theta_{i}, l_{i}, u_{i} \mid x_{i}, f_{i}, J_{i}, S_{i-1} ; \Phi_{2}\right)$. The basic intuition behind this assumption is that the location of the band immediately after a realignment depends only on the exchange rate and the shadow exchange rate but not on the parameters describing their dynamics in (6) and (7). ${ }^{7}$ For the problem of maximizing the

\footnotetext{
${ }^{7}$ Since the realignment occurs immediately before the observation of the new central parity and the new band width, this assumption is consistent with e.g. the modelling in Christensen et al. (1998) where both the exchange rate and central parity jump to the shadow exchange rate and the band width is held constant.
} 
likelihood function determined by (11) with respect to the parameters in $\Phi_{1}$, this assumption implies that we can ignore the conditional densities $p\left(\theta_{i}, l_{i}, u_{i} \mid x_{i}, f_{i}, J_{i}, S_{i-1} ; \Phi\right)$ in (11) since they do not depend on $\Phi_{1} \cdot{ }^{8}$ Specifically, the likelihood function for the estimation of the parameters in $\Phi_{1}$ is thus obtained by adopting the description of the density function in (11) and ignoring these conditional density terms. The remaining part of (11) depends entirely on the conditional densities implied by the discretized system in (6) and (7) as well as the jump probabilities in (3) and (8).

As noted above, the relevant likelihood function is a function of the parameters in $\Phi_{1}$ as well as the empirical observations. The expression in (11) describes the likelihood of the implied state-vectors $S_{i}=\left(x_{i}, f_{i}, \theta_{i}, l_{i}, u_{i}\right)$ while the empirical observations are $\left(x_{i}, r_{i}, \theta_{i}, l_{i}, u_{i}\right)$. In order to obtain the likelihood in terms of the empirical observations we will apply the change-of-variable formula which involves the Jacobian determinant of the transformation between the empirical observations and the state-vector $S_{i}$. In our case, the Jacobian determinant reduces to the partial derivative of the implied shadow exchange rate $f_{i}$ (as described in (5)) with respect to the interest rate spread $r_{i}$. Using the change-of-variable formula, the relevant log-likelihood function for estimation can be written on the following form,

$$
\begin{aligned}
l\left(\Phi_{1}\right) & =\sum_{i=1}^{I} \log \left(\left|\frac{\partial f_{i}}{\partial r_{i}}\right| p\left(x_{i}, f_{i}, J_{i} \mid S_{i-1} ; \Phi_{1}\right)\right) \\
& =\sum_{i=1}^{I} \log \left|\frac{\partial f_{i}}{\partial r_{i}}\right|+\sum_{i=1}^{I} \log p\left(x_{i}, f_{i} \mid J_{i}, S_{i-1} ; \Phi_{1}\right)+\sum_{i=1}^{I} \log p\left(J_{i} \mid S_{i-1} ; \Phi_{1}\right)
\end{aligned}
$$

where

$$
p\left(J_{i} \mid S_{i-1} ; \Phi_{1}\right)= \begin{cases}e^{-\lambda_{i-1} \Delta} & \text { if } J_{i}=0 \\ 1-e^{-\lambda_{i-1} \Delta} & \text { if } J_{i}=1\end{cases}
$$

and

$$
p\left(x_{i}, f_{i} \mid J_{i}, S_{i-1} ; \Phi_{1}\right)=\frac{1}{2 \pi\left|V_{i}\right|^{1 / 2}} e^{-\frac{1}{2} m_{i} V_{i} m_{i}^{\prime}}
$$

with

$$
m_{i}^{\prime}=\left\{\begin{array}{cc}
\left(\begin{array}{c}
f_{i}-f_{i-1}-\mu \Delta \\
x_{i}-x_{i-1}-\left[a\left(\theta_{i-1}-x_{i-1}\right)+b_{i-1}\left(f_{i-1}-x_{i-1}\right)\right] \Delta
\end{array}\right) & \text { if } J_{i}=0 \\
\left(\begin{array}{c}
f_{i}-f_{i-1}-\mu \Delta \\
x_{i}-f_{i}
\end{array}\right) & \text { if } J_{i}=1
\end{array}\right.
$$

\footnotetext{
${ }^{8}$ Moreover, $\left(x_{t}, f_{t}, J_{i}\right)$ is weakly exogenous for inference about $\Phi_{2}$; see Engle et al. (1983), Definition 2.5 .
} 


$$
V_{i}=\left\{\begin{array}{cc}
\left(\begin{array}{cc}
\sigma^{2} \Delta & \rho \sigma \delta \sqrt{\frac{4\left(u_{i}-x_{i}\right)\left(x_{i}-l_{i}\right)}{\left(u_{i}-l_{i}\right)^{2}}} \Delta \\
\rho \sigma \delta \sqrt{\frac{4\left(u_{i}-x_{i}\right)\left(x_{i}-l_{i}\right)}{\left(u_{i}-l_{i}\right)^{2}}} \Delta & \delta^{2} \frac{4\left(u_{i}-x_{i}\right)\left(x_{i}-l_{i}\right)}{\left(u_{i}-l_{i}\right)^{2}} \Delta
\end{array}\right) & \text { if } J_{i}=0 \\
\left(\begin{array}{cc}
\sigma^{2} \Delta & 0 \\
0 & w^{2}
\end{array}\right) & \text { if } J_{i}=1
\end{array}\right.
$$

The parameter estimates of the target zone model reported in the following section are obtained by maximizing the log-likelihood function (13) with respect to $\Phi_{1}$.

\section{Empirical results}

In this section we will describe the data and estimation results. Furthermore, we will discuss the parameter estimates and present filtered shadow exchange rates. Finally, we will analyze issues concerning macroeconomic determinants of misalignment on the short run and long run.

\subsection{Data}

The data consists of weekly observations on exchange rates and 1-month Euro market interest rates. Data was collected for the seven countries which have been involved in the ERM since March 13, 1979. The exchange rate data consists of exchange rates for the six currencies: Belgian franc (BEF), Danish kroner (DKK), French franc (FRF), Irish pound (IEP), Italian lira (ITL), and Dutch guilder (NLG) versus the German mark (DEM). The data for the short interest rates consists of the interest rate spreads between the 1-month Euro market interest rates in the same six European countries and the 1-month Euro market rate for the German mark. The Euro market interest rates are bid rates collected at around 10 a.m. Swiss Time; the interest rate data was supplied by the Bank for International Settlements (BIS).

The data series span from March 13, 1979 until June 25, 1997 (November 4, 1981 until June 25, 1997 for the Irish pound). The data is available on a daily basis, but since there might be small discrepancies in the exact time of the day for the sampling of the exchange rate observations and the Euro market interest rate observations, we have chosen to use weekly data. The data consists of observations on Wednesdays (Thursday if Wednesday is not available) and we have 955 weekly observation dates for all currencies except the Irish pound for which we have 817 weekly observation dates. 


\subsection{Target zone estimation results}

In implementing the approximate maximum likelihood method as described above, we experienced some identification problems when running the problem unrestricted for the six individual currencies. ${ }^{9}$ As a consequence, we fix two parameters to be equal for all the six currencies in the results reported below.

The two parameters we find reasonable to fix a priori are the parameters $\omega$ and $\lambda_{0}$ which are parameters that describe the timing as well as what happens at a realignment date. Since only a few realignments are observed for each exchange rate (two for the Dutch guilder versus German mark exchange rate to eleven for the Italian lira versus German mark exchange rate) it is obviously difficult to obtain reliable estimates on these parameters; the parameter $\lambda_{1}$ also describes the timing of realignments during periods of speculative pressure on the target zone and is estimated as part of the general approximate maximum likelihood estimation problem outlined in Section 3. Our specific reasoning and the concrete choice of parameter values for $\omega$ and $\lambda_{0}$ are described in the following.

At a realignment date, the (log-) exchange rate will jump to the (log-) shadow exchange rate plus some "noise"; the parameter $\omega$ describes the standard deviation of this noise term. In the estimation results reported below, we fix this standard deviation at a 0.25 percent level, i.e. $\omega=0.0025$, which reflects our subjective view of the part of a realignment jump which can be attributed to "noise". ${ }^{10}$

The parameter $\lambda_{0}$ describes the intensity of a realignment when the specific currency is not under pressure versus the German mark; see the discussion of equation (3). When the currency is not under pressure, the realignment intensity is constant as in a standard Poisson process. Moreover, a reasonable (maximum likelihood) estimator of the intensity in a Poisson process is the number of jumps divided by the process time. Hence, this parameter is calibrated by the ratio of number of jumps to the amount of time spent not under pressure for the total of the six currencies. The position of the exchange rate within the band is used as a proxy for whether the currency is under pressure or not. If the exchange rate is below the central parity, we view the exchange rate as not being under pressure. This is based on the reasoning that the German mark is usually the "strong" currency within the ERM and,

\footnotetext{
${ }^{9}$ This problem shows up when inverting the Hessian matrix of the log-likelihood problem at the optimal parameter estimates in order to obtain standard errors.

${ }^{10}$ This e.g. implies that if there is a realignment jump and the shadow exchange rate is $F_{t} \equiv e^{f_{t}}=1$, there is a $95 \%$ probability that the exchange rate will be in the interval [0.9951,1.0049] after the realignment jump.
} 
therefore, if there is a pressure on a specific currency versus the German mark, it will be at the upper boundary of the band. The number of realignments when the exchange rate is in the lower part of the band in the data sample is three (one for DKK, one for ITL, and one for IEP). The total time spent in the lower part of the band is 44.71 years and the estimate of the intensity parameter is obtained as $\lambda_{0}=3 / 44.71=0.0671$.

The estimates obtained by maximizing the log-likelihood function in (13), with restrictions on $\omega$ and $\lambda_{0}$, are presented in Table $1 .^{11}$

\section{[ INSERT TABLE 1 ABOUT HERE ]}

We will provide our interpretation of the parameter estimates in the following discussion. Moreover, the implied shadow exchange rates in the subsequent empirical analysis are filtered out using the tabulated parameter estimates.

The credibility of the target zone is reflected through at least the parameters $\mu, a$, and $\lambda_{1}$. The parameter $\mu$ determines the drift rate of the shadow exchange rate and thus indicates the sustainability of a given target zone. Specifically, if the parameter $\mu$ is different from zero, it is not likely that a specific target zone band can be sustained over long time periods since the shadow exchange rate will tend to drift outside the band and will thus inevitably put the target zone under pressure at some time point. The parameter estimates in Table 1 indicate that the drift rate of the Dutch guilder shadow exchange rate is not significantly different from zero $(\mu=0.0010)$ while the parameter estimates of $\mu$ for the other currencies versus German mark are all positive. The highest estimate of $\mu$ is obtained for the Italian lira versus German mark $(\mu=0.0619)$ which indicates a low sustainability of this particular target zone; this is not a surprising result having in mind the frequent target zone adjustments of the Italian lira versus German mark in the estimation period.

High credibility of a target zone is also associated with a high parameter value of $a$, which describes the tendency towards the central parity, and a low parameter value of $\lambda_{1}$, which describes the realignment intensity during periods where the exchange rate is under pressure. The highest parameter estimate of $a$ and the lowest parameter estimate of $\lambda_{1}$ are obtained for the Dutch guilder $\left(a=0.1560\right.$ and $\left.\lambda_{1}=56.29\right)$ which again indicate high credibility of the target zone for the Dutch guilder versus German mark. ${ }^{12}$ The lowest estimate of the

\footnotetext{
${ }^{11}$ The band for the Italian lira was suspended in the period from September 17, 1992 until November 25, 1996. In the estimation procedure, we handled this problem by imposing a very wide band in the period; 1000 percent on each side of the exchange rate.

${ }^{12}$ The finding that the Dutch guilder versus German mark exchange rate shows the highest degree of mean
} 
tendency towards the central parity is obtained for the Italian lira $(a=0.0473)$ and the existence of a target zone thus has the weakest implications for the mean-reverting behavior of the Italian lira against German mark exchange rate within the ERM band. Likewise, the highest estimate of $\lambda_{1}$ is obtained for the Italian lira $\left(\lambda_{1}=1162.83\right)$ which in addition suggests that this target zone is considered very likely to be adjusted whenever the Italian lira is close to the boundaries of the band.

As indicated in the above discussion, the parameter estimates in Table 1 indicate two polar case: a credible Dutch guilder target zone and a non-credible Italian lira target zone. In this perspective, we will interpret the other parameter estimates.

The parameter $\kappa$ describes the degree of tendency of the exchange rate towards the shadow exchange rate that takes place continuously and not as a discontinuous realignment jump. The lowest parameter estimate of $\kappa$ is obtained for the Dutch guilder target zone $(\kappa=0.9299)$ while the highest estimate is obtained for the Italian lira target zone $(\kappa=5.3490)$. A low estimate of $\kappa$ can, in our view, be interpreted as indicating a well-functioning (credible) target zone in the sense that the tendency towards the center of the target zone (as described by the parameter $a$ ) tends to dominate the tendency to the shadow exchange rate for low values of $\kappa$.

The parameter $\rho$ describes the degree of correlation between the managed exchange rate and the shadow exchange rate. A low estimate (2. lowest) of $\rho$ is obtained for the Dutch guilder target zone $(\rho=0.2804)$ while the highest estimate of $\rho$ is obtained for the Italian lira target zone $(\rho=0.9628)$. In particular, low estimates of $\rho$ indicate that fluctuations in the shadow exchange rate have relatively low impact on the short run behavior of the managed exchange rate; this is the case for the Dutch guilder versus German mark. On the other hand, non-credible target zones, such as the Italian lira target zone, tend to be associated with a high instantaneous feed-back between the managed exchange rate and the shadow exchange rate as reflected in high estimates of $\rho$.

The parameter $\delta$ describes the volatility of the exchange rate within the band while the parameter $\sigma$ describes the volatility of the shadow exchange rate. The lowest estimate of $\delta$ is obtained for the Dutch guilder target zone $(\delta=0.0113)$ while the second highest estimate is obtained for the Italian lira $(\delta=0.0563)$. The parameter estimates of $\sigma$ exhibit the same pattern; lowest for the Dutch guilder $(\sigma=0.0240)$ and highest for the Italian lira $(\sigma=$ 0.0576). If the shadow exchange rate is interpreted as the exchange rate without a target reversion is consistent with the findings in Anthony \& MacDonald (1998). 
zone being imposed, it makes intuitively sense that a volatile shadow exchange rate also induces a volatile managed exchange rate within the target zone. Moreover, the estimates in Table 1 indicate that a low volatility of the managed exchange rate is related to a high credibility of the target zone.

As noted above, the Dutch guilder target zone and the Italian lira target zone provide two polar cases. The estimates of the parameters for the Belgium franc target zone are consistently similar to the estimates of the Dutch guilder target zone but less evident and, hence, the results indicate a relatively high credibility of the Belgian franc target zone. For the other target zones the results are mixed and less clear, though, the parameter estimates are in general in between the two polar cases of the Dutch guilder target zone and the Italian lira target zone. In the discussion below we will focus on the French franc target zone which in our view seems to have some special characteristics.

The parameter estimates of the French franc target zone are striking since the results are somehow mixed in relation to the above discussion of credible versus non-credible target zones. In particular, the French franc versus German mark exchange rate exhibits high volatility within the band as reflected in the highest estimate of $\delta(\delta=0.0621)$. This suggests a low credibility of the French franc target zone. On the other hand, the lowest estimate of the correlation between the managed exchange rate and the shadow exchange rate is also obtained for the French franc $(\rho=0.2431)$ which, referring to the above discussion, indicates a high credibility of the French franc target zone. Anyhow, the remaining parameter estimates of the French franc target zone model are in between the two polar cases of the Dutch guilder and Italian lira target zones which all and all suggest that the French franc target zone is less credible than the Dutch guilder target zone but more credible than the Italian lira target zone.

Finally, note that the French franc target zone has a particular feature that differs from the other target zones since the French franc shadow exchange rate is seemingly significantly less volatile than the managed exchange rate in the center of the target zone band ( $\sigma=$ $0.0410<0.0621=\delta$ ). This is somehow surprising since a basic motivation for imposing a target zone on the exchange rate is to reduce the overall exchange rate uncertainty. The high estimate of $\delta$ for the French franc target zone may be caused by an inflexible functional form imposed on the volatility term of the managed exchange rate in the particular case of the French franc target zone (see Figure 2). For example, Bekaert and Gray (1998) present evidence indicating that the volatility of the managed exchange rate may be higher close to 
the boundaries than in the center of the target zone for the French franc versus German mark target zone. We will not pursue this issue further in this context.

\subsection{Plots of the shadow exchange rates}

Although the parameter estimates in Table 1 have interest on their own, an additional important purpose with this paper is to provide some filtering estimates regarding the position of the shadow exchange rates during the estimation period. These are obtained by inserting the obtained parameter estimates and by inverting the relation between the interest rate spread and the shadow exchange rate as in equation (5). The filtered shadow exchange rates as well as exchange rate data, interest rate data, and ERM band data are plotted in Figure 3 to Figure 8.

\section{[ INSERT FIGURE 3 TO 8 ABOUT HERE ]}

At least two features of the plots in Figure 3 to 8 deserve special attention. First, with the exception of the Dutch guilder shadow exchange rate, all shadow exchange rates are generally positioned "above" the exchange rate. Second, the plot of the Italian shadow exchange rate is interesting because the relatively high interest rate spread is not reflected in a high degree of misalignment, as measured by $f_{t}-x_{t}$. Hence, the non-credibility of this particular target zone in some sense implies low stabilizing properties of the target zone and at the same time the frequent realignments exclude the possibility of large differences between the shadow exchange rate and the managed exchange rate.

In addition to these general remarks on the basic properties of the filtered shadow exchange rates, we would like to point out that the procedure used in this paper can possibly add another dimension to the question of whether exchange rates have been misaligned before periods of currency turmoils and, if so, agents have been able to recognize such misalignments and trade domestic relative to foreign assets at an increasing interest rate spread. The literature on this issue is well developed. For instance, Svensson (1993), Rose \& Svensson (1994), and Chen \& Giovannini (1997) subtract the expected change of the exchange rate within the target zone band from the interest rate differential to study credibility of the target zone (the so-called drift-adjustment method); Campa \& Chang (1998) compute realignment intensities from ERM cross-rate options in order to study the economic determinants of these; and Bekaert \& Gray (1998) study credibility of the French franc target zone by specifically incorporating the possibility of jumps into their empirical model. 
Below we proceed along the lines of an alternative strategy: we filter out $f_{t}$ as described above and then look at whether exchange rates have been increasingly misaligned in the running up to periods of currency turmoils. Actually, in Figure 9, the degree of misalignment (defined as $f_{t}-x_{t}$ ) for the ERM currencies are shown. The plots indicate that there have been a number of occasions where exchange rates were being increasingly misaligned before realignments - for instance, the paths of $f_{t}-x_{t}$ preceding a number of realignments in the early 1980s are increasing for at least some of currencies.

\section{[ INSERT FIGURE 9 ABOUT HERE ]}

For the currency crises in 1992-1993, on the other hand, only for the Italian lira and the Irish pound, a clear increase in the spread $f_{t}-x_{t}$ before the September 1992 respectively the February 1993 realignment is visible in Figure 9. Perhaps to a lesser extent this is also the case for the Belgian franc and Danish kroner but is seemingly not the case for the French franc. This indicates that the financial markets considered only the Irish pound and the Italian lira as being fundamentally misaligned during the ERM-turmoils in 1992-1993.

Furthermore, over the whole period, the hypothesis of zero misalignment is clearly rejected (tests are not shown ${ }^{13}$ ) and this holds even if the hypothesis of no misalignment is tested over the period after the Basle-Nyborg agreement in September 1987, after the increase in number of participants in the ERM in 1990, or after 1992, i.e. the ERM currencies have throughout the ERM history generally been misaligned in relation to the German mark - and this holds for all exchange rates. For the Dutch guilder, though, the degree of misalignment seems to work in the opposite direction in the sense that for $N L G, f_{t}-x_{t}$ is negative throughout the last part of the sample. However, supplementing the results on a general misalignment of ERM exchange rates, it is noted that the degree of misalignment has decreased in recent years which could point towards increasing convergence between ERM currencies before introducing the euro on January 1, 1999.

\subsection{Determinants of degree of misalignment}

In addition to the question of currency crises "predictability" as reflected through increased misalignment, a number of recent articles deals with the extent to which specific macroeconomic variables are correlated with measures of speculative pressures and realignment expectations. In this section, we follow the approach of Eichengreen et al. $(1994,1995,1996)$

\footnotetext{
${ }^{13}$ Specifically, we tested whether the mean of the degree of misalignment, $f_{t}-x_{t}$, is equal to zero.
} 
and Campa \& Chang (1998) and focus on a specific period of exchange rate turmoil. To this end, we estimated the models,

$$
\left(f_{t}-x_{t}\right)=\text { cons. }+\gamma_{m} m_{t}+\gamma_{r} r_{t}^{L}+\gamma_{y} y_{t}+\gamma_{\pi} \pi_{t}+\gamma_{R} R_{t}+\gamma_{q} q_{t}+\zeta_{t}
$$

over the period January 1991 to December $1994^{14}$, where $m_{t}$ denotes the logarithm of relative (domestic versus foreign) nominal money (M1), $r_{t}^{L}$ denotes relative interest rates on long government bonds, $y_{t}$ denotes (the logarithm of) relative industrial production, $\pi_{t}$ denotes (the logarithm of) relative rates of inflation, $R_{t}$ denotes (the logarithm of) relative levels of official reserves excluding gold, $q_{t}$ measures the (logarithm of) bilateral real exchange rates towards Germany, and $\zeta_{t}$ is a regression residual. The macroeconomic data was obtained from the Main Economic Indicators, OECD. As macroeconomic variables are available up to a monthly frequency only, we obtained series for $x_{t}$ and $f_{t}$ at the monthly frequency by averaging over the weekly observations.

\section{[ INSERT TABLE 2 ABOUT HERE ]}

Table 2 shows parameter estimates of (14). ${ }^{15}$ A potentially important result from the table is the significant estimates of $\gamma_{R}$ for Belgium, France, Ireland, and Italy. On average, a one percentage decrease in relative reserves are associated with a 0.55 percentage increase in the degree of misalignment. This has potentially important bearings for the literature on speculative attacks, as the more recent second-generation models (see e.g. Obstfeld, 1996) are often seen specified in terms of other variables than official reserves, which play a crucial role in first-generation models of speculative attacks (see e.g. Krugman, 1979 or Flood \& Garber, 1984). First-generation models versus second-generation models are surveyed and discussed in e.g. Obstfeld (1994, 1996), Krugman (1996), and Flood \& Marion (1997).

A second variable which seems to be of some importance is the relative long interest rates, which is significant for Belgium, France, Ireland, and Italy. A one percentage increase in the spread between a domestic and a foreign long interest rate is associated with an increase in the degree of misalignment of, on average, 0.50 percentage. This is consistent with Ozkan

\footnotetext{
${ }^{14}$ Campa \& Chang (1998) estimate their model over the September 1991 to March 1995 period, whereas Eichengreen et al. $(1994,1995,1996)$ employ exclusion windows of two years before and after a currency crises in their analyses. In our estimation of (14) we essentially combine these two approaches.

${ }^{15}$ As some first-order autocorrelation was left in the residuals after running the basic OLS regression of (14), we corrected for this feature in the final regressions.
} 
\& Sutherland (1998) who provide a theoretical model with a positive relation between long interest rates and probabilities of speculative attacks.

To compare, Rose \& Svensson (1994) and Chang \& Campa (1998) generally find explanatory power of official foreign reserves, as do Chen \& Giovannini (1997) and Bekaert \& Gray (1998) for France, whereas Rose \& Svensson (1994) furthermore find differentials between rates of inflation to be significant over the whole 1979 to 1992 period. In general, though, the overall conclusion from this analysis (and previous analyses) is that traditional macroeconomic variables have a hard time in explaining the short-run turbulence in exchange rates or realignment expectations during times of currency turmoils as only relatively few variables are found to be significant.

\subsection{Long-run determinants of the shadow exchange rates}

Having pointed towards some characteristics of the degree of misalignment during turbulent periods of time, it seems natural to investigate whether the lacking explanatory power of traditional macroeconomic variables is a general characteristic for the shadow exchange rates which holds also over longer time spans. We investigate this by analyzing the standard monetary approach to exchange rates. The basic monetary equation for example follows from assuming a quantity equation in each country, $m_{t}^{i}-p_{t}^{i}=y_{t}^{i}, i=D, F$, imposing purchasing power parity (which, for the shadow exchange rates, takes the form $f_{t}=p_{t}^{D}-p_{t}^{F}$ ) and reorganizing,

$$
f_{t}=m_{t}-y_{t}
$$

to which a regression constant, $v$, and a stationary error term can be added.

When interpreting estimates of (15) it is noted that in general we expect (15) to hold only for floating exchange rates and not necessarily for exchange rates in a target zone. Consider

e.g. the basic Krugman (1991) model of a target zone. A prominent feature of this model is that the target zone imposes a S-shaped form on the exchange rate within the band, i.e. monetary disturbances are transmitted only partially to the exchange rate (the "honeymoon effect"). In this sense, a change in $m_{t}$ does not cause an instantaneously one-to-one change in the exchange rate. In our model, however, $f_{t}$ is estimated exactly to give the behavior of the exchange rate if no target zone is present. Therefore, a reasonable hypothesis is that the shadow exchange rate behaves like a floating rate and that the relationship in (15) is appropriate. 
In the analyses of the long-run behavior of the shadow exchange rates, we recognize that the shadow exchange rates tend to move in a non-stationary fashion (see also Figure 3 to 8 ) and for this reason we employ the multivariate cointegration framework of Johansen (1988, $1991,1995)$ in order to obtain estimates of the long run attractors for the filtered shadow exchange rates. ${ }^{16}$ We thus estimated vector error correction models such as,

$$
\Delta Y_{t}=\alpha \beta^{* \prime} \widetilde{Y}_{t-1}^{*}+\sum_{i=1}^{11} \Gamma_{i} \Delta \widetilde{Y}_{t-i}+\psi d 846+\varepsilon_{t}
$$

with $Y=\left(f_{t}, m_{t}, y_{t}\right)^{\prime}, \tilde{Y}_{t}=\left(f_{t}, m_{t}, y_{t}, d 901\right)^{\prime}$, and $\tilde{Y}_{t}^{*}=\left(\widetilde{Y}_{t}^{\prime}, 1\right)^{\prime}$, where $d 911$ and $d 846$ are dummies and $\beta^{* \prime}$ is the matrix of cointegration vectors, the rank of which, if cointegration can be established, is less than the dimension of $Y_{t}$, i.e. less than three. ${ }^{17}$

In testing for cointegration, we followed Johansen (1992) who advocates the use of a sequential testing strategy; the so-called "Pantula-principle", so as to test for restrictions on the constant. We ended up restricting the constant to enter the cointegration space only, as in $(16)$.

\section{[ INSERT TABLE 3 ABOUT HERE ]}

The tests for the number of cointegration vectors are given in Table 3 for the models where the constant is restricted to the cointegration space. ${ }^{18}$ The results point toward rejection of both the hypotheses of at most zero and at most one cointegration vector, i.e. we decided on two cointegration vectors in all models. Our next step was to look for a monetary equation as a long-run attractor for the shadow exchange rates. We therefore tested whether $f_{t}-$

\footnotetext{
${ }^{16}$ In addition, the continuous time target zone model superimposes non-stationarity of $f_{t}$; see equations (1) and (6).

${ }^{17}$ In July 1990, former East and West Germany joined GEMU (German Economic and Monetary Union) having the German mark replacing the (East) German currency as legal tender. Obviously, this caused a significant positive jump in German money supply influencing all $m_{t}=m_{t}^{D}-m_{t}^{F}$ series negatively. In order to take this jump into account, we follow Juselius (1996) and include a dummy (d911; taking on the value 0 for periods between 1979:3 and 1990:12 and the value 1 in periods between 1991:1 and 1997:6) as a weakly exogenous variable. Furthermore, the German production series takes a massive dip in 1984:6 which influences all $y_{t}$ series and to take this into account we included a dummy (d846) taking on the value 1 in period 1984:6 and zero otherwise.

${ }^{18}$ We included twelve lags in our final regression which seems as a reasonable number given the sample frequency of monthly observations. Reassuring though, the basic results were not altered when running the cointegration models with other choices for the lag length.
} 
$\left(m_{t}-y_{t}+\phi d 911+v\right)$ can be accepted as a stationary series. The results and the estimated cointegration vectors are given in Table 4.

\section{[ INSERT TABLE 4 ABOUT HERE ]}

It appears that for five out of the six currencies under investigation, the hypothesis that the monetary equation acts as a long-run attractor for the filtered shadow exchange rates cannot be rejected at standard significance levels. Only for the French franc the hypothesis is rejected. Hence, the results support the basic monetary equation in the sense that we cannot reject an unit elasticity of the shadow exchange rates with respect to the relative money supplies and the relative production series, respectively. Furthermore, the estimated coefficient of the dummy $d 911$ associated with the German unification is positive. The positive jump in $m_{t}^{F}$, and thus the negative jump in $m_{t}$, dictates a negative jump in the shadow exchange rates if described by the monetary equation in (15); however, these negative jumps are to some extent adjusted for by the dummy $d 911$.

In general, the results in Table 4 indicate that the shadow exchange rates, on the long run, do behave in accordance with a standard theory of exchange rate determination. This is consistent with the findings of e.g. McDonald \& Taylor (1993, 1994), Mark (1995), Chinn \& Meese (1995), and Mark \& Choi (1997) in the context of floating exchange rates.

\section{Conclusions}

We have investigated the dynamics of exchange rates and interest rate spreads in a target zone using a two step procedure. In the first step we presented a continuous time target zone model where the exchange rate was restricted to move within a band but was allowed to leave the band by a jump. We estimated the model for six ERM exchange rates and extracted the relevant shadow exchange rates. In the second step, we regressed the degree of misalignment (the difference between the filtered shadow exchange rate and the managed exchange rate) on six macroeconomic variables. Basically, the results indicated some support of first-generation models in the sense that exchange reserves were correlated with the degree of misalignment during the 1992-1993 ERM turmoil for the involved exchange rates. Likewise, a cointegration analysis provided some evidence for the monetary equation as a long run attractor for five (out of six) shadow exchange rates.

In line with most of the literature on target zones, the analysis in this paper has been restricted to bilateral exchange rates. This is admittedly a simplification since the ERM is a 
multi-lateral target zone (a grid of bands on bilateral currencies) with a number of bilateral exchange rates being targeted simultaneously. This has, for instance, the implication that a currency which is actually within the bilateral band towards another currency can be affected by the intervention against a third currency; see e.g. the analyses in Jørgensen \& Mikkelsen (1996) or Flandreau (1998). The continuous time framework in this paper can potentially be extended to incorporate such features; of course, at the costs of higher complexity.

Moreover, when estimating the parameters of the target zone model, one could potentially extend the analysis by incorporating data on cross-rate options, as in e.g. Campa \& Chang $(1996,1998)$. This would be interesting in models that extends the framework of the present paper, but would require some additional numerical work as no close-form option pricing formulas exist.

Finally, we believe that the specific modelling in this paper can be extended in different directions. For example, one may allow for a more general specification of the dynamics of the shadow exchange rate. Likewise, the dynamics of the managed exchange rate may be generalized to allow for stochastic volatility within the band; i.e. the parameter $\delta$ in (2) may be replaced by a stochastic process. 


\section{Appendix}

In this appendix we will demonstrate the existence of a pricing kernel process that makes the model in Section 2 consistent with "uncovered interest rate parity" in the sense that the interest rate spread equals the expected change of the log-exchange rate. In fact, below we will demonstrate that the following pricing kernel process provides such consistency,

$$
d K_{t}=-\left[r_{t}^{D}+\lambda_{t}\left(\bar{J}_{t}-1\right)\right] K_{t} d t-\frac{1}{2} \delta_{t} K_{t} d W_{2 t}+\left(J_{t}-1\right) K_{t} d N_{t}
$$

where the relative jump size $\left(J_{t}-1\right)$ is stochastic and $\left(\bar{J}_{t}-1\right)$ denotes the expected relative jump size. Moreover, $\delta_{t}$ is used as notation for the whole diffusion coefficient in the diffusion term for the log-exchange rate in (2) (see also (20) below). The relative jump size can be chosen on the form,

$$
J_{t}-1=\frac{\left(f_{t}-x_{t}\right) e^{-\frac{1}{2} \epsilon_{t}-\frac{1}{8} \omega^{2}}}{e^{\frac{1}{2}\left(f_{t}-x_{t}\right)}-e^{-\frac{1}{2}\left(f_{t}-x_{t}\right)}}-1 \text { and } \bar{J}_{t}-1=\frac{\left(f_{t}-x_{t}\right) e^{-\frac{1}{2}\left(f_{t}-x_{t}\right)}}{e^{\frac{1}{2}\left(f_{t}-x_{t}\right)}-e^{-\frac{1}{2}\left(f_{t}-x_{t}\right)}}-1
$$

where $\epsilon_{t}=\left(f_{t}-x_{t}\right)+\eta_{t}$ and $\eta_{t} \sim \operatorname{NID}\left(0, \omega^{2}\right)$.

By definition of a pricing kernel process, we can price any financial asset by evaluating the relevant expectations. Consider a claim having stochastic payoff in units of the domestic currency, $S_{T}$, at some future date $T>t$. Then the present value of this claim (in units of the domestic currency) must satisfy,

$$
S_{t}=\mathrm{E}_{t}\left[\frac{K_{T}}{K_{t}} S_{T}\right]
$$

In a representative agent equilibrium set-up, the pricing kernel is identical to the marginal utility of the representative agent and prices are found by marginal utility weighted payoffs; see e.g. Lucas (1978) for the discrete time case and Cox et al. (1985a) for the continuous time case. In general, the mere absence of arbitrage ensures the existence of a pricing kernel process such that all asset prices satisfy (19); see e.g. Duffie (1996).

The above assumptions on the form of the pricing kernel process are conceptually different from those in Christensen et al. (1997). Compared to the pricing kernel process in (17), they basically consider a kernel process where the diffusion term and the jump size are zero. This implies that the interest rate spread equals the rate of change in the exchange rate, $X_{t} \cdot{ }^{19}$

\footnotetext{
${ }^{19}$ However, due to Siegel's paradox, it is well-known that the interest rate spread will not equal the rate of change for $\left(1 / X_{t}\right)$, i.e. the exchange rate quoted inversely. In our case, specifying the model in logarithms ensures that the "uncovered interest rate parity" is valid regardless of how the exchange rate is quoted.
} 


\section{A.1 Pricing contingent claims by simulations}

Using the result in (19), it is straightforward to price any exchange rate contingent claim by simulations. The model, however, only provides sufficient structure to determine the interest rate spread, not the level of interest rates. Hence, it is necessary to provide a model for the level of interest rates. One approach is to assume that the foreign interest rate is a positive constant or follows a square root process; as in Cox et al. (1985b). As these interest rate models ensure positive interest rates and since the interest rate spread versus German mark is usually positive, this reduces problems concerning the possibility of negative interest rates within the model.

If we fix the foreign interest rate, a simulation approach for evaluating prices on exchange rate contingent claims, using the expectations in (19), can have the following form. A number of paths of the exchange rate process and pricing kernel process is generated (using discretizations of the stochastic differential equations involved). At every time point, the domestic interest rate occurring in (17) is found by using the "uncovered interest rate parity". The price is then obtained as the average of the simulated values of the kernel weighted payoffs. This simulation method provides a natural procedure for evaluating prices on contingent claims that cannot be exercised before maturity. Even with the possibility of early exercise, a simulation approach based on the expectations in (19) can be designed to evaluate, say, American currency option prices; see e.g. Barraquand \& Martineau (1995).

\section{A.2 Consistency of "uncovered interest rate parity"}

In the following we will demonstrate that the target zone model in Section 2 and the pricing kernel process in (17) are consistent with the assumption of "uncovered interest rate parity".

The dynamics of the log-exchange rate, $x_{t}$, can be summarized by,

$$
d x_{t}=m_{t} d t+\delta_{t} d Z_{2 t}+\epsilon_{t} d N_{t}
$$

where we have introduced $m_{t}$ and $\delta_{t}$ as notation for the drift term and diffusion term, respectively. The precise definitions of $m_{t}$ and $\delta_{t}$ follow from (2). By an application of Ito's lemma for jump-diffusion processes, the dynamics of the exchange rate, $X_{t}=e^{x_{t}}$, must satisfy:

$$
d X_{t}=\left(m_{t}+\frac{1}{2} \delta_{t}\right) X_{t} d t+\delta_{t} X_{t} d Z_{2 t}+\left(e^{\epsilon t}-1\right) X_{t} d N_{t}
$$

We will assume that there exist a domestic and foreign bank account which provide a risk 
free rate of return equal to the domestic and foreign short interest rates. The accumulated returns on the bank accounts are described by $B_{t}^{i}=e^{\int_{0}^{t} r_{u}^{i} d u}, i=D, F$.

In the following, we will refer to a domestic investor as an investor who is concerned about the return on investments in units of the domestic currency. From the perspective of a domestic investor, an investment in the domestic bank account accumulates according to,

$$
d B_{t}^{D}=r_{t}^{D} B_{t}^{D} d t
$$

whereas an investment in the foreign bank account is exposed to exchange rate risk and accumulates according to (again using Ito's lemma for jump-diffusion processes):

$$
d\left(X_{t} B_{t}^{F}\right)=\left(m_{t}+\frac{1}{2} \delta_{t}+r_{t}^{F}\right)\left(X_{t} B_{t}^{F}\right) d t+\delta_{t}\left(X_{t} B_{t}^{F}\right) d Z_{2 t}+\left(e^{\epsilon t}-1\right)\left(X_{t} B_{t}^{F}\right) d N_{t}
$$

The kernel weighted return on the foreign bank account investment can, likewise, be described by an application of Ito's lemma for jump-diffusion processes,

$$
\begin{aligned}
d\left(K_{t} X_{t} B_{t}^{F}\right)=\left(-r_{t}^{D}\right. & \left.-\lambda_{t}\left(\bar{J}_{t}-1\right)+m_{t}+r_{t}^{F}\right)\left(K_{t} X_{t} B_{t}^{F}\right) d t \\
& +\frac{1}{2} \delta_{t}\left(K_{t} X_{t} B_{t}^{F}\right) d Z_{2 t}+\left(J_{t} e^{\epsilon t}-1\right)\left(K_{t} X_{t} B_{t}^{F}\right) d N_{t} .
\end{aligned}
$$

where the relative jump size $\left(J_{t} e^{\epsilon_{t}}-1\right)$ and the expected relative jump size $\left(\left(\overline{J_{t} e^{\epsilon_{t}}}\right)-1\right)$, by the definition of $J_{t}$ given in (18), can be written on the form:

$$
J_{t} e^{\epsilon_{t}}-1=\frac{\left(f_{t}-x_{t}\right) e^{\frac{1}{2} \epsilon_{t}-\frac{1}{8} \omega^{2}}}{e^{\frac{1}{2}\left(f_{t}-x_{t}\right)}-e^{-\frac{1}{2}\left(f_{t}-x_{t}\right)}}-1 \text { and }\left(\overline{J_{t} e^{\epsilon_{t}}}\right)-1=\frac{\left(f_{t}-x_{t}\right) e^{\frac{1}{2}\left(f_{t}-x_{t}\right)}}{e^{\frac{1}{2}\left(f_{t}-x_{t}\right)}-e^{-\frac{1}{2}\left(f_{t}-x_{t}\right)}}-1
$$

The expected change in the kernel weighted foreign bank account investment is given by,

$$
\begin{aligned}
\mathrm{E}_{t}\left[d\left(K_{t} X_{t} B_{t}^{F}\right)\right] & =\left[-\left(r_{t}^{D}-r_{t}^{F}\right)+m_{t}+\lambda_{t}\left(\left(\overline{J_{t} e^{\epsilon t}}\right)-\bar{J}_{t}\right)\right]\left(K_{t} X_{t} B_{t}^{F}\right) d t \\
& =\left[-\left(r_{t}^{D}-r_{t}^{F}\right)+m_{t}+\lambda_{t}\left(f_{t}-x_{t}\right)\right]\left(K_{t} X_{t} B_{t}^{F}\right) d t
\end{aligned}
$$

where the second equality is obtained by inserting the expected relative jump sizes in (18) and (25). From the equilibrium asset pricing relation in (19), it is seen that the kernel weighted foreign bank account investment must be a martingale and, hence, the expected rate of change must equal zero. Setting the expected rate of change in (27) equal to zero, as an equilibrium implication, one obtains,

$$
r_{t}^{D}-r_{t}^{F}=m_{t}+\lambda_{t}\left(f_{t}-x_{t}\right)
$$

which is the "uncovered interest rate parity". 
Following the above steps, it can be verified that the pricing kernel, $K_{t}$, ensures that a kernel weighted investment in the domestic bank account is likewise a martingale. This ends the demonstration of the consistency of the "uncovered interest rate parity" and a specific pricing kernel process in the economy. 


\section{References}

Anthony, Myrvin \& Ronald MacDonald (1998). "On the mean-reverting properties of target zone exchange rates: Some evidence from the ERM". European Economic Review, 42(8), $1493-1523$.

Ball, Clifford A. \& Antonio Roma (1993). "A jump diffusion model for the European Monetary System". Journal of International Money and Finance, 12(5), 475-492.

Barraquand, Jerome \& Didier Martineau (1995). "Numerical Valuation of High Dimensional Multivariate American Securities". Journal of Financial and Quantitative Analysis, 30(3), 383-405.

Bekaert, Geert \& Stephen F. Gray (1998). "Target Zones and Exchange Rates: An Empirical Investigation". Journal of International Economics, 45(1), 1-35.

Bertola, Giuseppe \& Ricardo J. Cabellero (1992). "Target Zones and Realignments". The American Economic Review, 82(3), 520-536.

Bossaerts, Peter \& Pierre Hillion (1991). "Market Microstructure Effects of Government Intervention in the Foreign Exchange Market". Review of Financial Studies, 4(3), 513541.

Campa, Jose Manuel \& Kevin Chang (1996). "Arbitrage-based Tests of Target-zone Credibility: Evidence from ERM Cross-rate Options". American Economic Review, 86(4), $726-740$.

Campa, Jose Manuel \& Kevin Chang (1998). "ERM Realignment Risk and its Economic Determinants as Reflected in Cross-rate Options". Economic Journal, 108, 1046-1066.

Chen, Zhaohui \& Alberto Giovannini (1994). "The Credibility of Adjustable Parities: The Experience of the European Monetary System". In Peter B. Kenen; Francesco Papadia, \& Fabrizion Saccomanni, editors, The International Monetary System, chapter 7, pp. 170-200. Cambridge University Press.

Chen, Zhaohui \& Alberto Giovannini (1997). "The Determinants of Realignment Expectations under the EMS: Some Empirical Regularities". European Economic Review, 41(9), $1687-1707$. 
Chinn, Menzie D. \& Richard A. Meese (1995). "Banking on Currency Forecasts: How Predictable is the Change in Money?". Journal of International Economics, 38(1/2), $161-178$.

Christensen, Peter O.; David Lando \& Kristian Miltersen (1998). "State-Dependent Realignments in Target Zone Currency Regimes". Review of Derivatives Research, 1(4), $295-323$.

Cox, John C.; Jonathan E. Ingersoll \& Steven A. Ross (1985a). "An Intertemporal General Equilibrium Model of Asset Prices". Econometrica, 53(2), 363-384.

Cox, John C.; Jonathan E. Ingersoll \& Steven A. Ross (1985b). "A Theory of the Term Structure of Interest Rates". Econometrica, 53(2), 385-407.

Duffie, Darrell (1996). Dynamic Asset Pricing Theory. Princeton University Press, Princeton, New Jersey, 2 edition.

Dumas, Bernard; Lars P. Jennergren \& Bertil Näslund (1995). "Realignment Risk and Currency Option Pricing in Target Zones". European Economic Review, 39, 1523-1544.

Eichengreen, Barry; Andrew K. Rose \& Charles Wyplosz (1994). "Speculative Attacks on Pegged Exchange Rates: An empirical exploration with special reference to the European Monetary System". CEPR Discussion Paper, 1060.

Eichengreen, Barry; Andrew K. Rose \& Charles Wyplosz (1995). "Exchange Market Mayheim: The antecedents and aftermath of speculative attacks". Economic Policy, 21, $251-296$.

Eichengreen, Barry; Andrew K. Rose \& Charles Wyplosz (1996). "Contagious Currency Crises: Firsts Tests". Scandinavian Journal of Economics, 98(4), 463-484.

Engle, Robert F.; David F. Hendry \& Jean-Francois Richard (1983). "Exogeneity". Econometrica, 51, 277-304.

Flandreau, Marc (1998). "The burden of intervention: externalities in multilateral exchange rates arrangements". Journal of International Economics, 45(1), 137-171.

Flood, Robert P. \& Peter M. Garber (1984). "Collapsing Exchange Rate Regimes: Some Linear Examples". Journal of International Economics, 17(1/2), 1-14. 
Flood, Robert P. \& Nancy P. Marion (1997). "Perspectives on the Recent Currency Crisis Literature". Working paper, Dartmouth College.

Flood, Robert P. \& Andrew K. Rose (1995). "Fixing Exchange Rates: A Virtual Quest for Fundamentals". Journal of Monetary Economics, 36(1), 3-37.

Flood, Robert P.; Andrew K. Rose \& Donald J. Mathieson (1991). "An Empirical Exploration of Exchange-Rate Target-Zones". Carnegie-Rochester Conference Series on Public Policy, 35, 7-77.

Johansen, Søren (1988). "The Statistical Analysis of Cointegration Vectors". Journal of Economic Dynamics and Control, 12(2), 231-254.

Johansen, Søren (1991). "Estimation and Hypothesis Testing of Cointegration Vectors in Gaussian Vector Autoregressive Models". Econometrica, 59(6), 1551-1580.

Johansen, Søren (1992). "Determination of the Cointegration Rank in the Presence of a Linear Trend". Oxford Bulletin of Economics and Statistics, 54(2), 383-397.

Johansen, Søren (1995). Likelihood Based Inference in Cointegrated Vector Autoregressive Models. Advanced Texts in Econometrics. Oxford University Press.

Johansen, Søren \& Katarina Juselius (1990). "Maximum Likelihood Estimation and Inference on Cointegration - With Applications to the Demand for Money". Oxford Bulletin of Economics and Statistics, 52(2), 169-210.

Johansen, Søren \& Katarina Juselius (1992). "Testing Structural Hypotheses in a Multivariate Cointegration Analysis of the PPP and the UIP for UK". Journal of Econometrics, $53(1-3), 211-244$.

Jørgensen, Bjørn N. \& Hans O. Æ. Mikkelsen (1996). “An Arbitrage Free Trilateral Target Zone Model". Journal of International Money and Finance, 15(1), 117-134.

Juselius, Katarina (1996). "An Empirical Analysis of the Changing Role of the German Bundesbank after 1983". Oxford Bulletin of Economics and Statistics, 58(4), 791-819.

Krugman, Paul R. (1979). "A Model of Balance of Payments Crises". Journal of Money, Credit, and Banking, 11(3), 311-325. 
Krugman, Paul R. (1991). "Target Zones and Exchange Rate Dynamics". The Quarterly Journal of Economics, 106, 669-682.

Krugman, Paul R. (1996). “Are Currency Crises Self-Fulfilling?”. In Ben S. Bernanke \& Julio J. Rotemberg, editors, NBER Macroeconomics Annual, pp. 345-407. The MIT Press.

Lando, David (1994). "On Cox Processes and Credit Risky Bonds". Working paper, University of Copenhagen, Institute of Mathematical Statistics.

Li, Kai (1998). "Exchange Rate Target Zone Models: A Bayesian Evaluation". Working paper, University of British Columbia. Forthcomming in Journal of Applied Econometrics.

Lindberg, Hans; Paul Söderlind \& Lars E. O. Svensson (1993). "Devaluation Expectations: The Swedish krona 1985-1992". The Economic Journal, 1170-1179.

Lucas, Robert E. (1978). "Asset Prices in an Exchange Economy". Econometrica, 46, 14291445 .

MacDonald, Ronald \& Mark P. Taylor (1993). "The Monetary Approach to the Exchange Rate: Rational Expectations, Long-run Equilibrium, and Forecasting". IMF Staff Papers, 40(1), 89-107.

MacDonald, Ronald \& Mark P. Taylor (1994). "The Monetary Model of the Exchange Rate: Long-run Relationships, Short-run Dynamics and how to beat a Random Walk". Journal of International Money and Finance, 13(3), 276-290.

Mark, Nelson C. (1995). "Exchange Rates and Fundamentals: Evidence on Long-Horizon Predictability". American Economic Review, 85(1), 201-218.

Mark, Nelson C. \& Doo-Yull Choi (1997). "Real Exchange-Rate Prediction over Longer Horizons". Journal of International Economics, 43(1/2), 29-60.

Obstfeld, Maurice (1994). "The Logic of Currency Crises". Banque de France - Cahiers économiques et monétaires, 43, 189-213.

Obstfeld, Maurice (1996). "Models of Currency Crises with Self-Fulfilling Features". European Economic Review, 40(3-5), 1037-1047. 
Osterwald-Lenum, Michael (1992). "A Note with Quantiles of the Asymptotic Distribution of the Maximum Likelihood Cointegration Rank Statistic: Four Cases". Oxford Bullitin of Economics and Statistics, 54(3), 461-471.

Ozkan, F. Gulcin \& Alan Sutherland (1998). "A Currency Crisis Model with an Optimizing Policy Maker". Journal of International Economics, 44(2), 339-364.

Rose, Andrew K. \& Lars E. O. Svensson (1994). "European Exchange Rate Credibility Before the Fall". European Economic Review, 38(6), 1185-1216.

Rose, Andrew K. \& Lars E. O. Svensson (1995). "Expected and Predicted Realignments: The FF/DM Exchange Rate during the EMS, 1979-1993". Scandinavian Journal of Economics, 97(2), 173-200.

Svensson, Lars E. O. (1992). "The Foreign Exchange Risk Premium in a Target Zone with Devaluation Risk". Journal of International Economics, 33(1), 21-40.

Svensson, Lars E. O. (1993). "Assessing Target Zone Credibility. Mean reversion and devaluation expectations in the ERM, 1979-1992". European Economic Review, 37(4), 763-802.

Velasco, Andrés (1996). "Fixed Exchange Rates: Credibility, flexibility, and multiplicity". European Economic Review, 40(3-5), 1023-1035. 
Table 1: Parameter estimates for the continuous time target zone model

\begin{tabular}{c|cccccc}
\hline \hline Parameter & $B E F$ & $D K K$ & $F R F$ & $I E P$ & $I T L$ & $N L G$ \\
\hline$\mu$ & 0.0220 & 0.0288 & 0.0237 & 0.0500 & 0.0619 & 0.0010 \\
& $(0.0044)$ & $(0.0061)$ & $(0.0094)$ & $(0.0050)$ & $(0.0037)$ & $(0.0049)$ \\
$\sigma$ & 0.0269 & 0.0302 & 0.0410 & 0.0453 & 0.0576 & 0.0240 \\
& $(0.0006)$ & $(0.0008)$ & $(0.0013)$ & $(0.0013)$ & $(0.0013)$ & $(0.0015)$ \\
$a$ & 0.0910 & 0.0645 & 0.0553 & 0.1551 & 0.0473 & 0.1560 \\
& $(0.0437)$ & $(0.0445)$ & $(0.0372)$ & $(0.0709)$ & $(0.0216)$ & $(0.0440)$ \\
$\kappa$ & 1.8305 & 3.2040 & 1.6279 & 2.4076 & 5.3490 & 0.9299 \\
& $(0.0607)$ & $(0.1326)$ & $(0.0623)$ & $(0.0876)$ & $(0.2013)$ & $(0.0730)$ \\
$\delta$ & 0.0284 & 0.0305 & 0.0621 & 0.0410 & 0.0563 & 0.0113 \\
& $(0.0007)$ & $(0.0007)$ & $(0.0014)$ & $(0.0011)$ & $(0.0013)$ & $(0.0003)$ \\
$\rho$ & 0.7145 & 0.5158 & 0.2431 & 0.9050 & 0.9628 & 0.2804 \\
& $(0.0222)$ & $(0.0329)$ & $(0.0328)$ & $(0.0088)$ & $(0.0030)$ & $(0.0519)$ \\
$\lambda_{1}$ & 149.90 & 550.71 & 310.81 & 225.35 & 1162.83 & 56.29 \\
& $(10.69)$ & $(44.58)$ & $(21.24)$ & $(16.15)$ & $(97.26)$ & $(6.25)$ \\
\hline \hline
\end{tabular}

Notes: Parameter estimates for the continuous time target zone model for the different currencies against German mark. Standard errors are obtained by inversion of the Hessian of the log-likelihood function and reported in parentheses below the estimates. The parameters $\omega$ and $\lambda_{0}$ are fixed a priori at $\omega=0.0025$ and $\lambda_{0}=0.0671$. 
Table 2: Macroeconomic determinants of ERM misalignments, 1991-1995

\begin{tabular}{|c|c|c|c|c|c|c|}
\hline & $B E F$ & $D K K$ & $F R F$ & IEP & $I T L$ & $N L G$ \\
\hline cons. & $\begin{array}{c}0.0056 \\
(0.0082)\end{array}$ & $\begin{array}{c}-0.1119^{*} \\
(0.0502)\end{array}$ & $\begin{array}{c}0.0028 \\
(0.0081)\end{array}$ & $\begin{array}{c}-0.0491^{* *} \\
(0.0098)\end{array}$ & $\begin{array}{l}0.0064^{*} \\
(0.0028)\end{array}$ & $\begin{array}{l}-0.0057 \\
(0.0061)\end{array}$ \\
\hline$\gamma_{m}$ & $\begin{array}{l}-0.0129 \\
(0.0223)\end{array}$ & $\begin{array}{c}-0.0429^{*} \\
(0.0180)\end{array}$ & $\begin{array}{c}0.0186 \\
(0.0160)\end{array}$ & $\begin{array}{l}-0.0096 \\
(0.0201)\end{array}$ & $\begin{array}{c}0.0123 \\
(0.0097)\end{array}$ & $\begin{array}{c}0.0042 \\
(0.0184)\end{array}$ \\
\hline$\gamma_{r^{L}}$ & $\begin{array}{l}0.0067^{*} \\
(0.0025)\end{array}$ & $\begin{array}{c}0.0003 \\
(0.0004)\end{array}$ & $\begin{array}{c}0.0102^{* *} \\
(0.0026)\end{array}$ & $\begin{array}{l}0.0110^{* *} \\
(0.0019)\end{array}$ & $\begin{array}{c}0.0008^{* *} \\
(0.0003)\end{array}$ & $\begin{array}{c}0.0010 \\
(0.0028)\end{array}$ \\
\hline$\gamma_{y}$ & $\begin{array}{c}0.0048 \\
(0.0185)\end{array}$ & $\begin{array}{c}-0.0218 \\
(0.0143)\end{array}$ & $\begin{array}{c}-0.0101 \\
(0.0299)\end{array}$ & $\begin{array}{c}-0.0493^{* *} \\
(0.0066)\end{array}$ & $\begin{array}{c}0.0077 \\
(0.0077)\end{array}$ & $\begin{array}{l}-0.0062 \\
(0.0092)\end{array}$ \\
\hline$\gamma_{\pi}$ & $\begin{array}{c}0.0047 \\
(0.0031)\end{array}$ & $\begin{array}{l}-0.0045 \\
(0.0044)\end{array}$ & $\begin{array}{c}0.0052 \\
(0.0035)\end{array}$ & $\begin{array}{c}0.0017 \\
(0.0012)\end{array}$ & $\begin{array}{l}-0.0020 \\
(0.0012)\end{array}$ & $\begin{array}{c}0.0027 \\
(0.0021)\end{array}$ \\
\hline$\gamma_{R}$ & $\begin{array}{c}-0.0082^{*} \\
(0.0034)\end{array}$ & $\begin{array}{c}0.0050 \\
(0.0036)\end{array}$ & $\begin{array}{c}-0.0098^{* *} \\
(0.0030)\end{array}$ & $\begin{array}{c}-0.0117^{* *} \\
(0.0027)\end{array}$ & $\begin{array}{c}-0.0035^{* *} \\
(0.0010)\end{array}$ & $\begin{array}{l}-0.0043 \\
(0.0025)\end{array}$ \\
\hline$\gamma_{q}$ & $\begin{array}{l}-0.0017 \\
(0.0018)\end{array}$ & $\begin{array}{c}-0.0016 \\
(0.0026)\end{array}$ & $\begin{array}{c}-0.0036 \\
(0.0019)\end{array}$ & $\begin{array}{l}-0.0018 \\
(0.0012)\end{array}$ & $\begin{array}{l}0.0014^{*} \\
(0.0007)\end{array}$ & $\begin{array}{l}-0.0005 \\
(0.0011)\end{array}$ \\
\hline \multicolumn{7}{|c|}{ Diagnostics } \\
\hline $\bar{R}^{2}$ & 0.72 & 0.58 & 0.63 & 0.89 & 0.84 & 0.71 \\
\hline F-test & 0.01 & 0.02 & 0.00 & 0.00 & 0.00 & 0.14 \\
\hline DW & 1.62 & 1.95 & 1.63 & 2.05 & 1.72 & 1.79 \\
\hline
\end{tabular}

Notes: The table shows estimates of (14) with corrections for first-order autocorrelation obtained by applying the two-step Cochrane-Orcutt procedure. Numbers in parentheses are standard errors. ${ }^{* *}$ respectively ${ }^{*}$ indicate rejection of the hypothesis that the specific coefficient equals zero at 99, respectively 95 , percentage confidence levels. F-test shows probability value of not rejecting the hypothesis that all coefficients equal zero, DW is the Durbin-Watson test statistic for firstorder autocorrelation. Number of observations: 48. 
Table 3: Tests for the number of cointegration vectors in the monetary models

\begin{tabular}{c|rccccc}
\hline \hline$r k(\beta) \leq$ & $B E F$ & $D K K$ & $F R F$ & $I E P$ & $I T L$ & $N L G$ \\
\hline 0 & $50.83^{* *}$ & $57.42^{* *}$ & $58.90^{* *}$ & $50.56^{* *}$ & $53.24^{* *}$ & $60.96^{* *}$ \\
1 & $22.85^{*}$ & $24.05^{*}$ & $26.25^{* *}$ & $25.66^{* *}$ & $28.66^{* *}$ & $25.73^{* *}$ \\
2 & $9.73^{*}$ & 7.77 & 8.05 & 7.76 & $12.13^{*}$ & 6.19 \\
\hline \hline
\end{tabular}

Notes: Tests for the number of cointegration vectors (Johansen \& Juselius, 1990). ${ }^{* *}$ respectively ${ }^{*}$ indicate rejection of hypothesis at 99 respectively 95 percentage confidence levels. Critical values at various significance levels are from Osterwald-Lenum (1992).

Table 4: Tests of the basic monetary equation lying within the stationary space

\begin{tabular}{lccc}
\hline \hline & $\chi^{2}(1)$ & Prob. & Estimated cointegration vectors \\
\hline Belgian franc: & 3.34 & 0.07 & $f_{t}-\left(m_{t}-y_{t}+0.31 \cdot d 911+3.02\right)$ \\
Danish kroner: & 0.06 & 0.80 & $f_{t}-\left(m_{t}-y_{t}+0.83 \cdot d 911+0.37\right)$ \\
French franc: & 10.07 & 0.00 & $f_{t}-\left(m_{t}-y_{t}+0.35 \cdot d 911+1.37\right)$ \\
Irish pound: & 0.75 & 0.39 & $f_{t}-\left(m_{t}-y_{t}+0.04 \cdot d 911-1.25\right)$ \\
Italian lira: & 1.50 & 0.22 & $f_{t}-\left(m_{t}-y_{t}+0.63 \cdot d 911+6.65\right)$ \\
Dutch guilder: & 0.44 & 0.51 & $f_{t}-\left(m_{t}-y_{t}+0.28 \cdot d 911+0.11\right)$ \\
\hline \hline
\end{tabular}

Notes: Tests for a cointegration vector with a unit coefficient on $y_{t}$ and a unit coefficient (with opposite sign) on $m_{t}$ belonging to the cointegration space. The constant and the coefficient on $d 911$ are left unrestricted; the tests have a standard $\chi^{2}$ distribution (Johansen \& Juselius, 1992). 


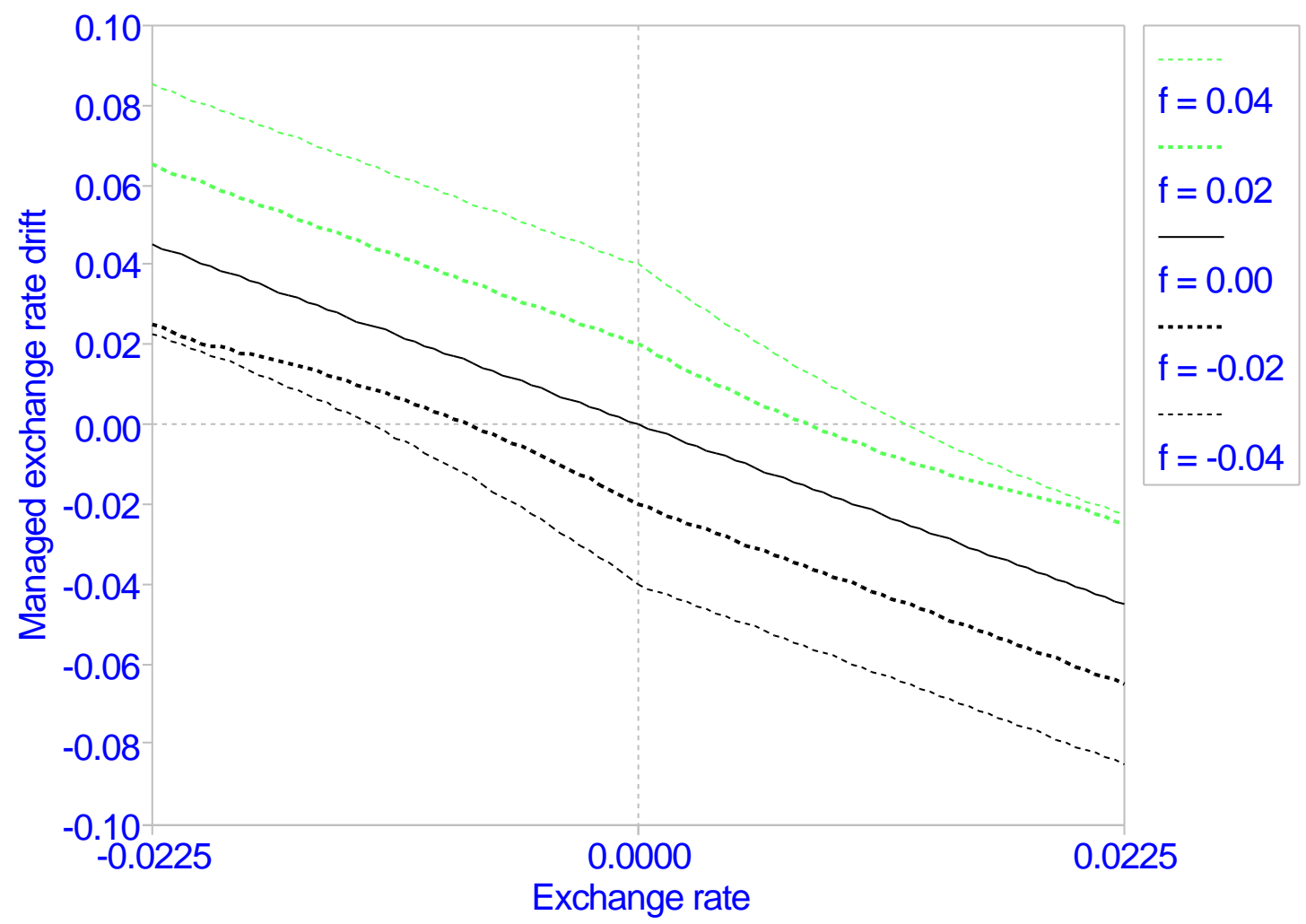

Figure 1: The drift of the managed exchange rate as a function of the current exchange rate within a target zone with $l_{t}=-0.0225, u_{t}=0.0225$, and $\theta=0$. The relevant parameters are $a=1$ and $\kappa=1$. 


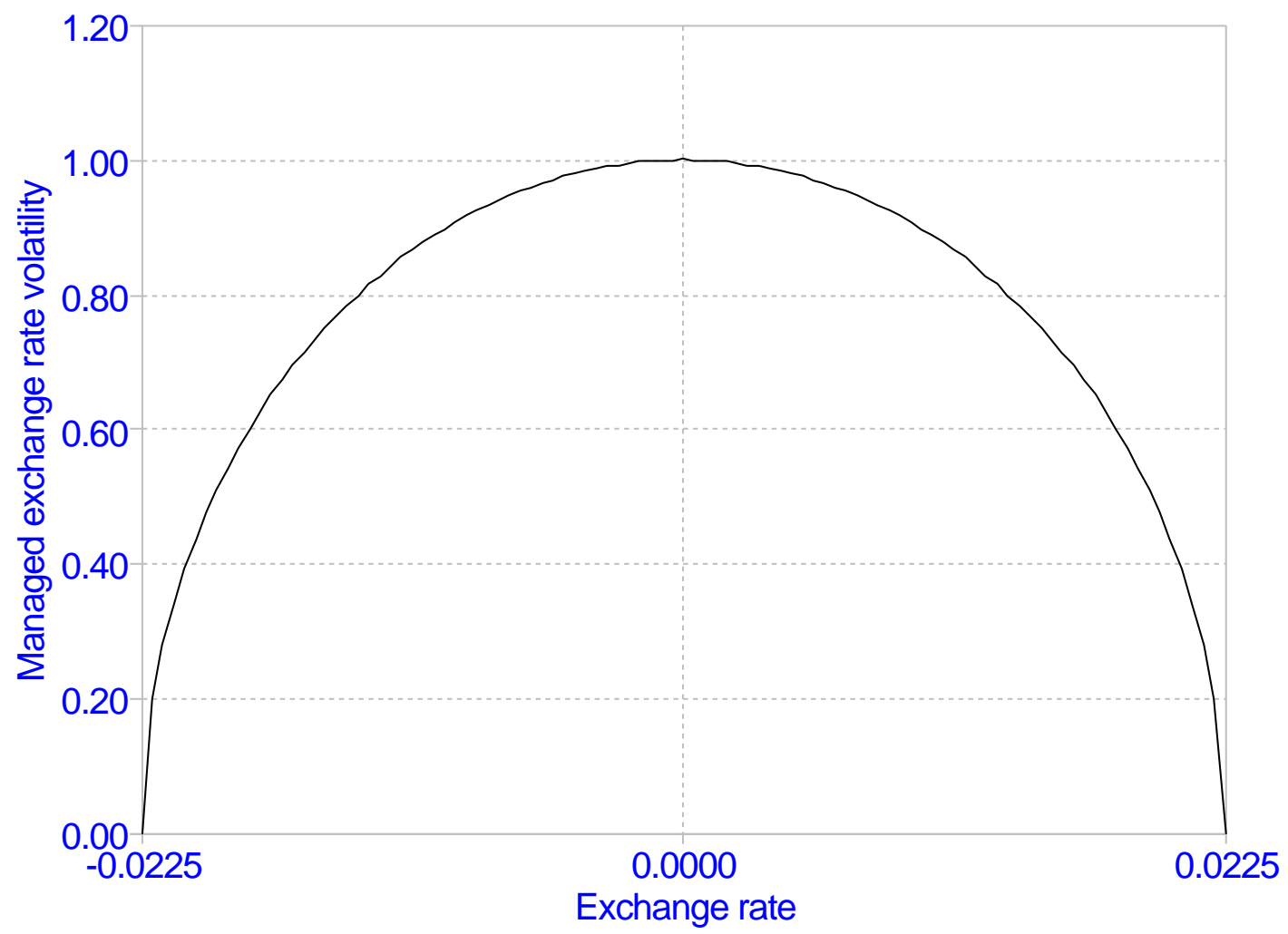

Figure 2: The volatility of the managed exchange rate as a function of the current exchange rate within a target zone with $l_{t}=-0.0225, u_{t}=0.0225$, and $\theta=0$. The volatility parameter is $\delta=1$. 


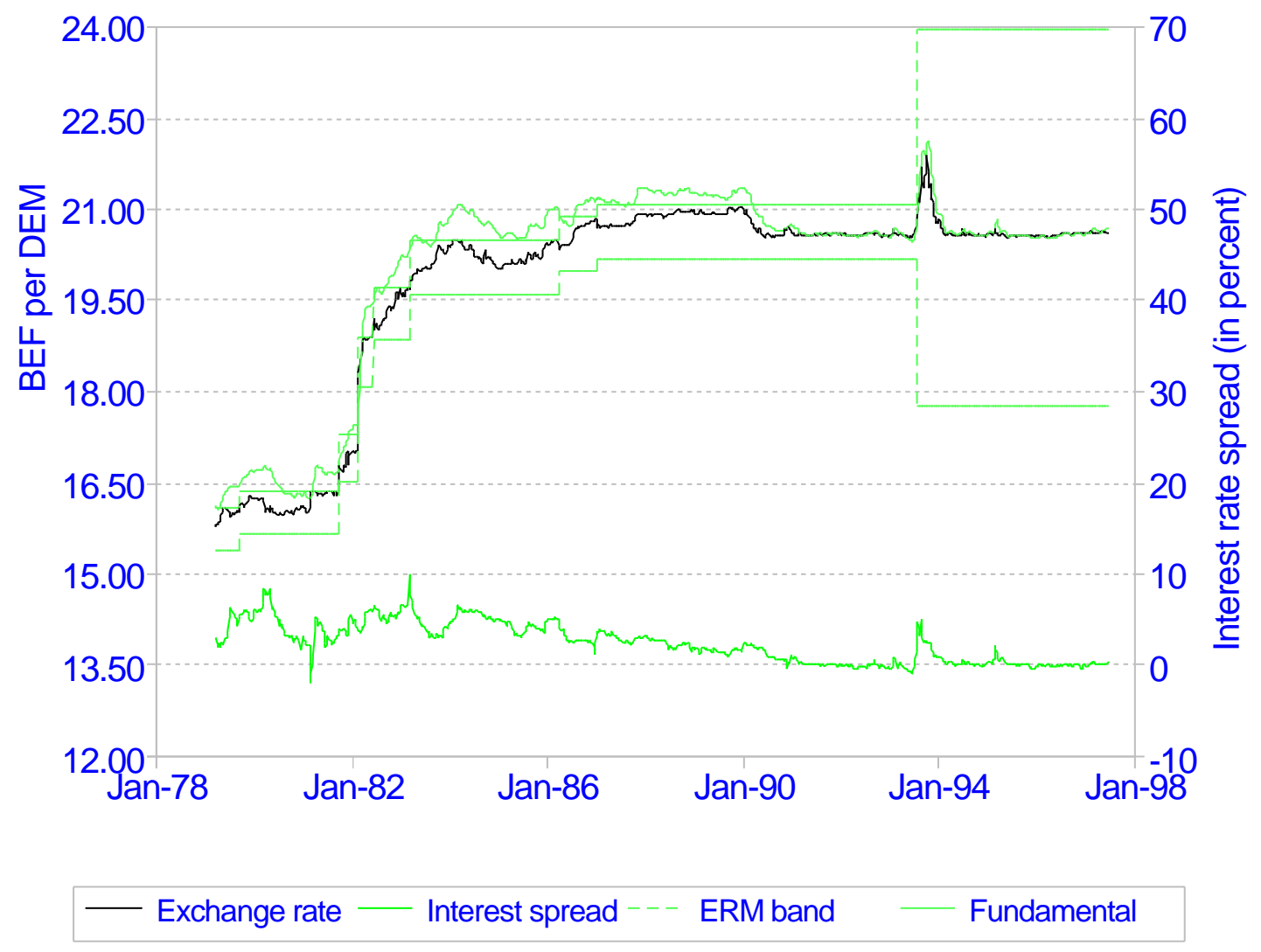

Figure 3: Time series of Belgian franc per German mark and the spread between 1-month Euro market interest rates for the two currencies. 


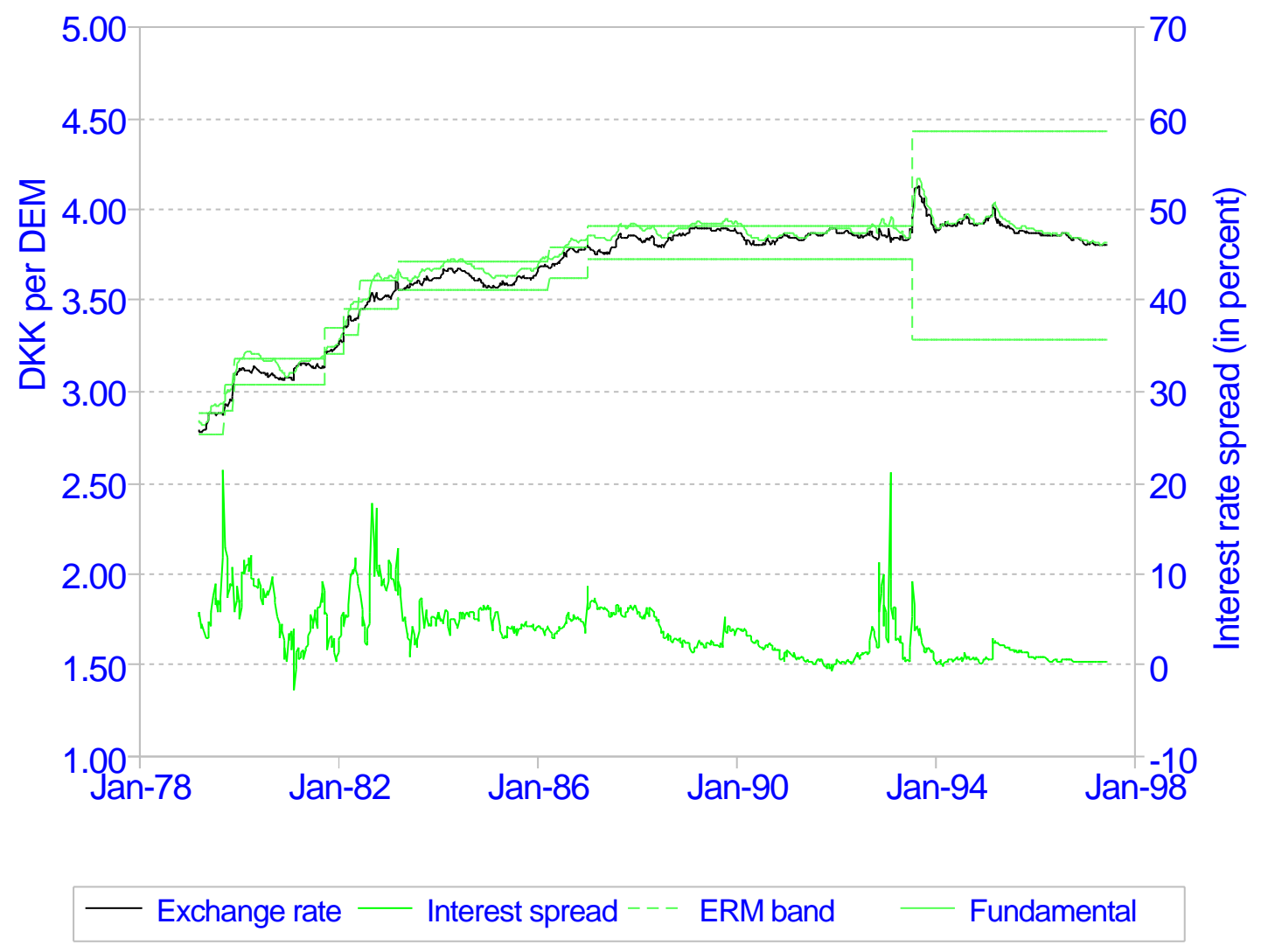

Figure 4: Time series of Danish kroner per German mark and the spread between 1-month Euro market interest rates for the two currencies. 


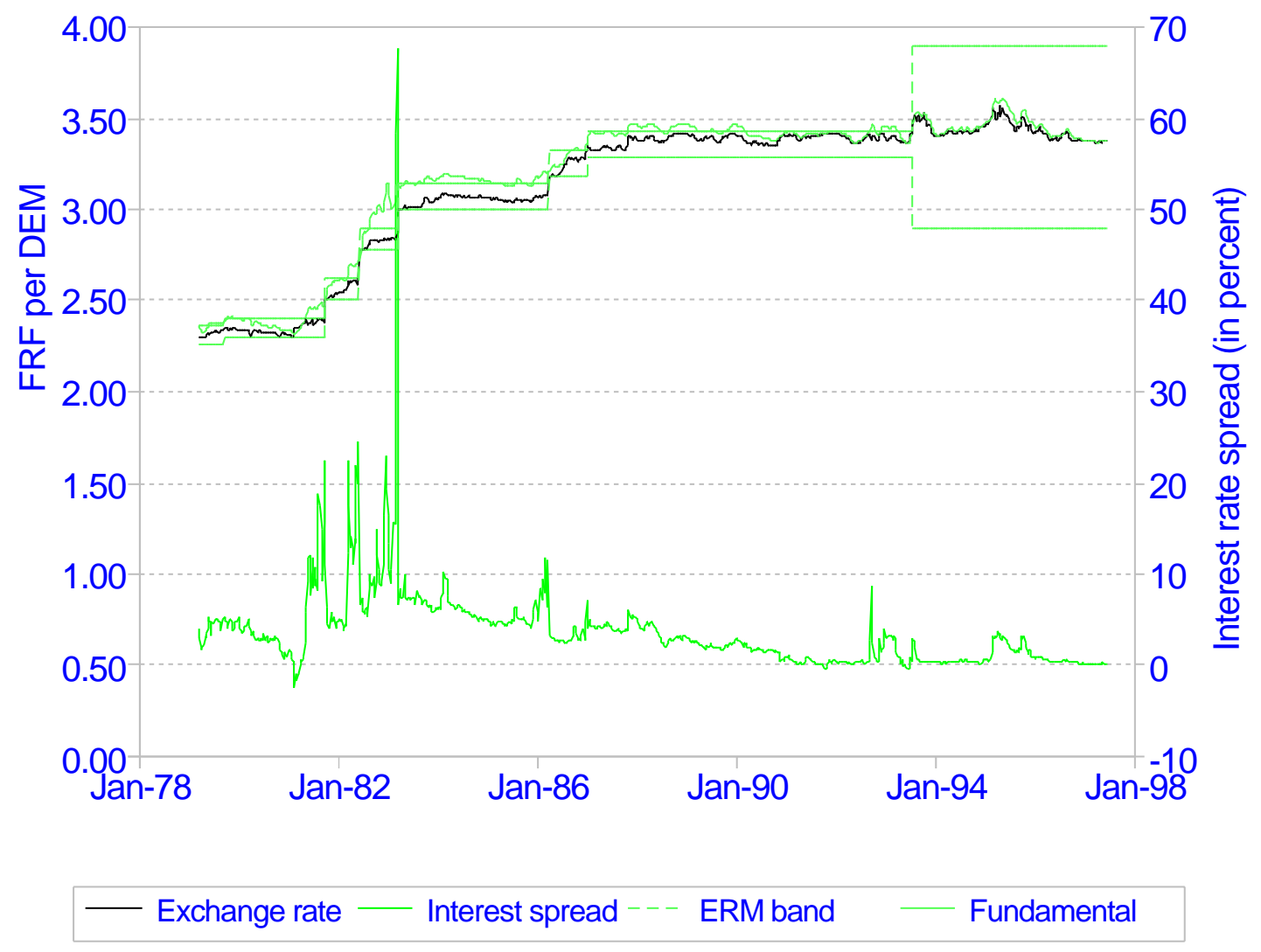

Figure 5: Time series of French franc per German mark and the spread between 1-month Euro market interest rates for the two currencies. 


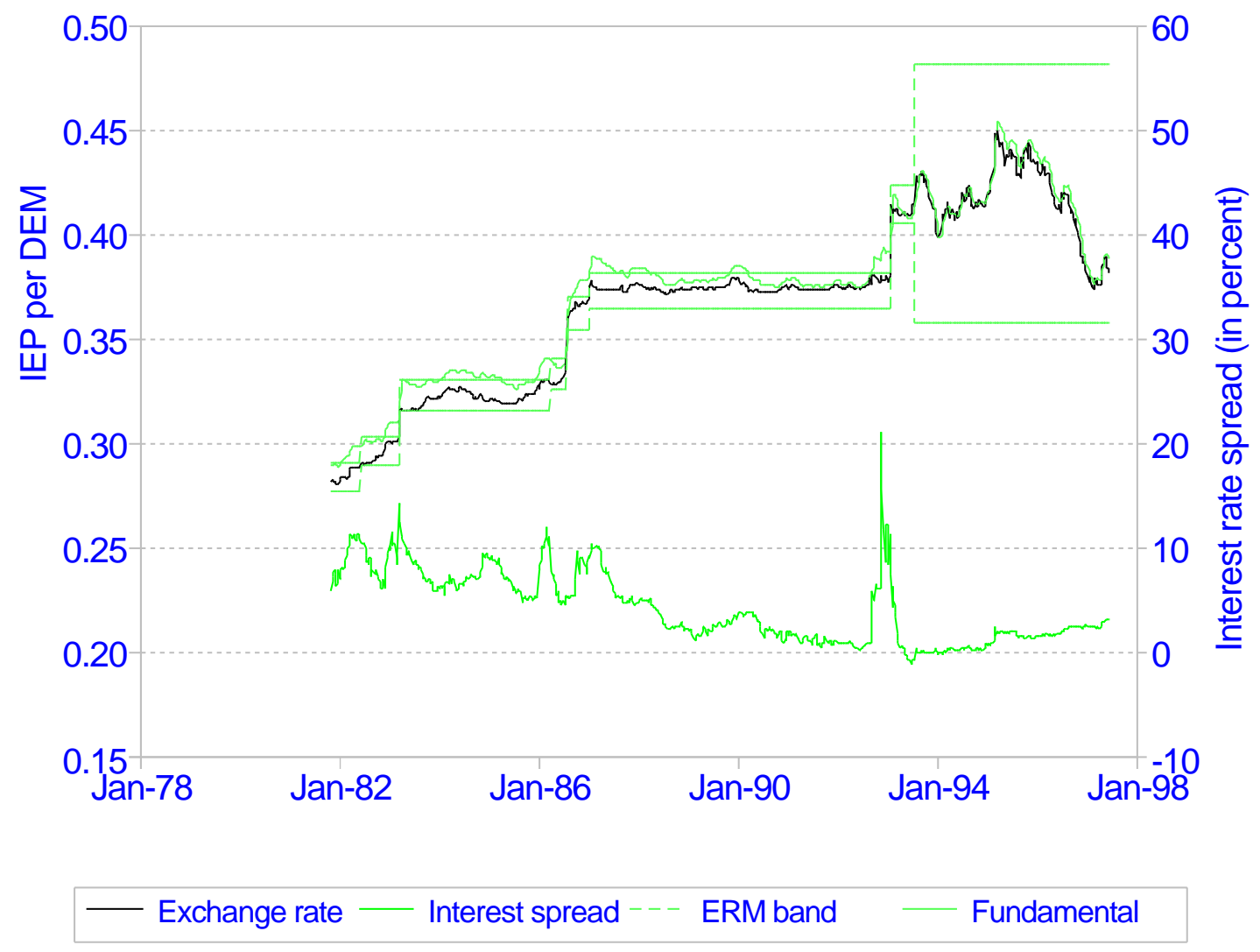

Figure 6: Time series of Irish pound per German mark and the spread between 1-month Euro market interest rates for the two currencies. 


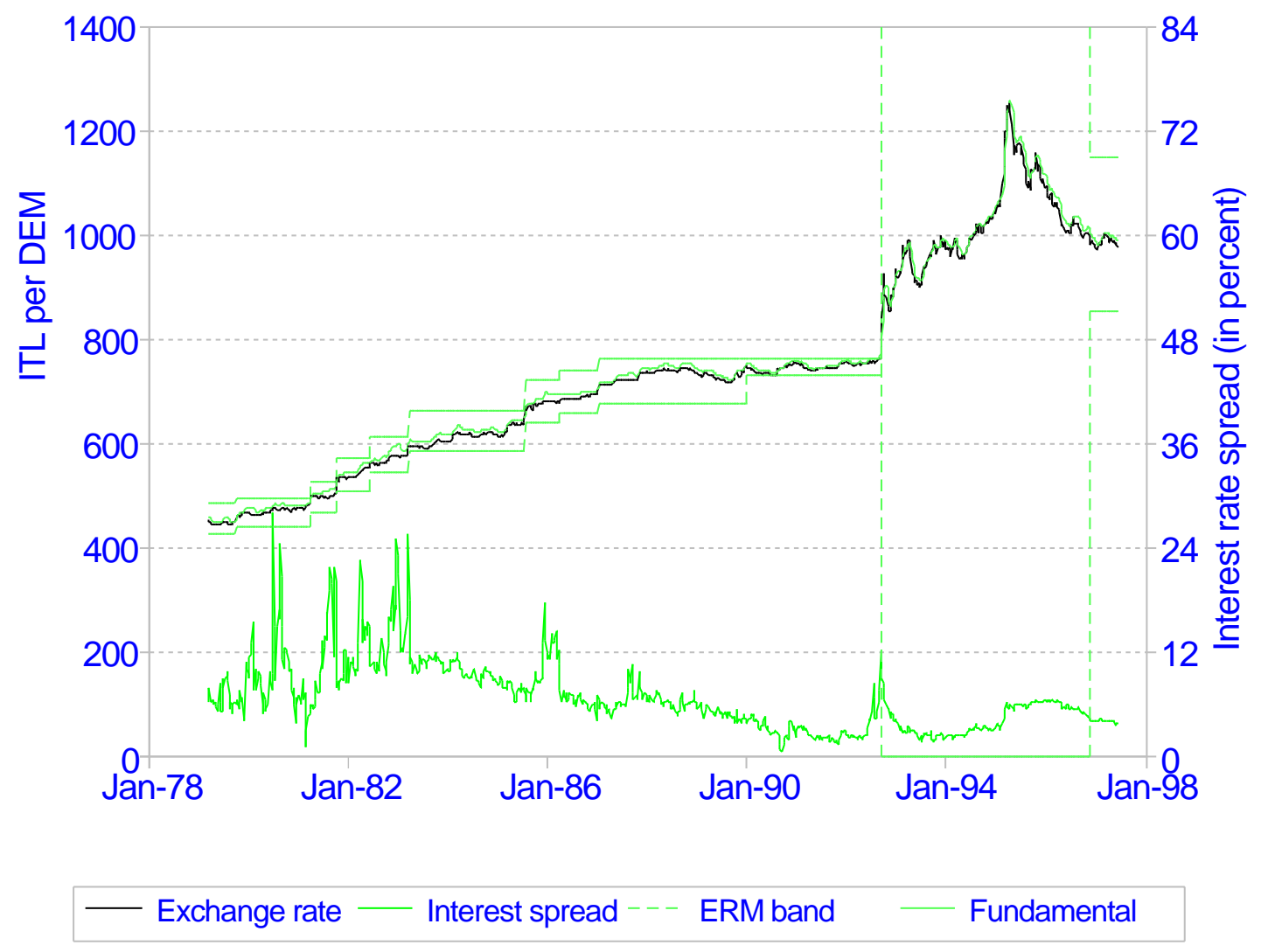

Figure 7: Time series of Italian lira per German mark and the spread between 1-month Euro market interest rates for the two currencies. 


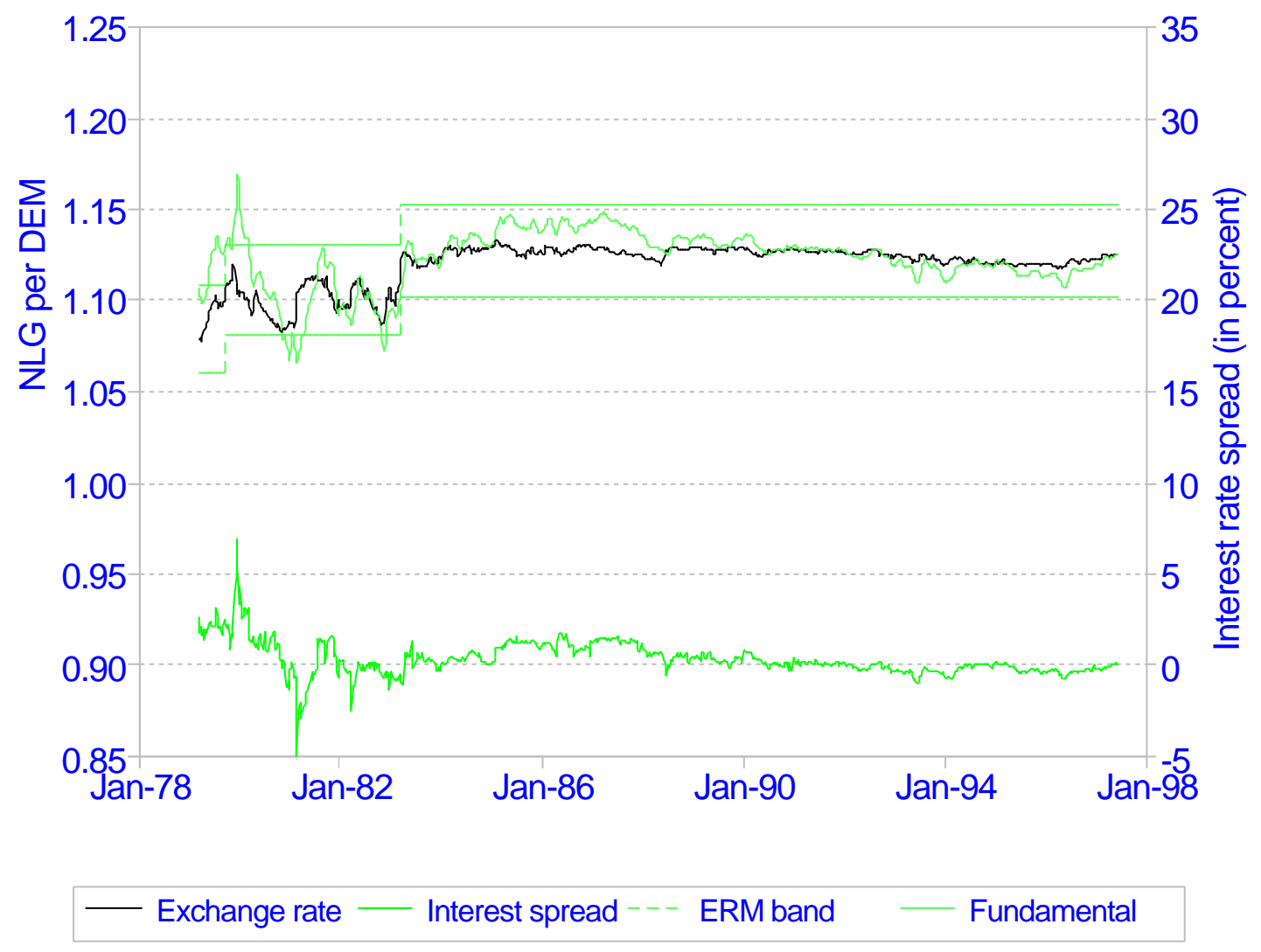

Figure 8: Time series of Dutch guilder per German mark and the spread between 1-month Euro market interest rates for the two currencies. 

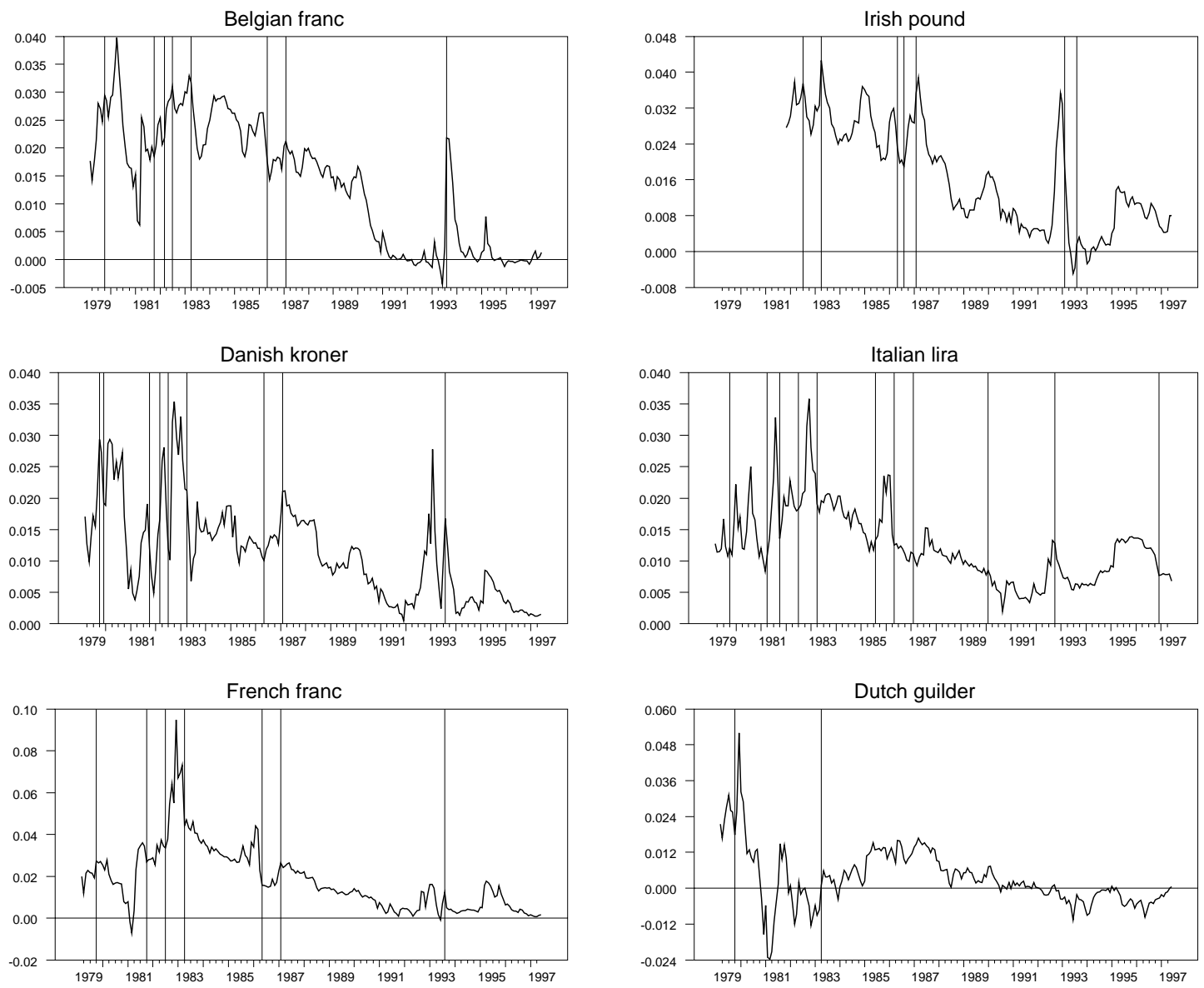

Figure 9: Time series of differences between shadow exchange rates and current exchange rates $\left(f_{t}-x_{t}\right)$ for the various currencies versus German mark. Realignment dates are indicated by vertical lines. 